\title{
Atypical Retinotopic Organization of Visual Cortex in Patients with Central Brain Damage: Congenital and Adult Onset
}

\author{
Danielle C. Reitsma, ${ }^{1}$ Jedidiah Mathis, ${ }^{1}$ John L. Ulmer, ${ }^{1}$ Wade Mueller, ${ }^{1}$ Mary J. Maciejewski, ${ }^{1,2}$ and Edgar A. DeYoe ${ }^{1}$ \\ ${ }^{1}$ The Medical College of Wisconsin, Milwaukee, Wisconsin 53226, and ${ }^{2}$ Marquette University, Milwaukee, Wisconsin 53233
}

It remains unclear to what extent retinotopic maps can undergo large-scale plasticity following damage to human visual cortex. The literature has predominately focused on retinotopic changes in patients with retinal pathologies or congenital brain malformations. Yet, damage to the adult visual cortex itself is common in cases such as stroke, tumor, or trauma. To address this issue, we used a unique database of fMRI vision maps in patients with adult-onset $(n=25)$ and congenital $(n=2)$ pathology of the visual cortex. We identified atypical retinotopic organization in three patients (two with adult-onset, and one with congenital pathology) consisting of an expanded ipsilateral field representation that was on average 3.2 times greater than healthy controls. The expanded representations were located at the vertical meridian borders between visual areas such as V1/V2. Additionally, two of the three patients had apparently an ectopic (topographically inconsistent) representation of the ipsilateral field within lateral occipital cortex that is normally associated with visual areas V3/V3A (and possibly other areas). Both adult-onset cases had direct damage to early visual cortex itself (rather than to the afferent drive only), resulting in a mostly nonfunctional hemisphere. The congenital case had severe cortical malformation of the visual cortex and was acallosal. Our results are consistent with a competitive model in which unilateral damage to visual cortex or disruption of the transcallosal connections removes interhemispheric suppression from retino-geniculate afferents in intact visual cortex that represent the vertical meridian and ipsilateral visual field.

\section{Introduction}

Damage to visual cortex is a common occurrence in cases of stroke, tumor, and trauma. Although there is a long history of studying the spatial organization of visual field maps (e.g., retinotopic maps) after direct damage (Inouye, 1909; Holmes and Lister, 1916; Spalding, 1952; Horton and Hoyt, 1991), early studies did not focus on identifying plastic changes consistent with reorganization or unmasking. The discovery that plastic changes in visual cortex organization might be limited to an early critical period of development (Wiesel and Hubel, 1963; Hubel and Wiesel, 1970, 1977) led to a common assumption that all cortical connections in the adult visual cortex are fixed. More recently, this assumption has been challenged by evidence of plasticity in early visual cortex evoked by changes in normal experience (for review, see Gilbert and $\mathrm{Li}, 2012$ ) and by damage to peripheral visual pathways, about which there is still considerable debate

\footnotetext{
Received Jan. 17, 2013; revised June 7, 2013; accepted June 20, 2013.

Author contributions: D.C.R. and E.A.D. designed research; D.C.R., J.M., J.U., W.M., and M.J.M. performed research; D.C.R. and E.A.D. analyzed data; D.C.R. wrote the paper.

This work was supported by National Institutes of Health (NIH) Grants R01EB000843 and R42CA113186 to E.A.D. and R01EB007827 to J.H. We thank Joseph Carroll and Adam Dubis for help with retinal imaging experiments, which were supported by the Thomas M. Aaberg, Sr, Retina Research Fund and NIH Grant P30EY001931. We also thank Bernd Remler and Lofti Hacien-Bey for additional patient referrals.

The authors declare no competing financial interests.

Correspondence should be addressed to Danielle C. Reitsma, The Medical College of Wisconsin, 8701 Watertown Plank Road, Milwaukee, WI 53226. E-mail: dreitsma@mcw.edu.

DOI:10.1523/JNEUROSCI.0240-13.2013

Copyright $\odot 2013$ the authors $\quad 0270-6474 / 13 / 3313010-15 \$ 15.00 / 0$
}

(for review, see Wandell and Smirnakis, 2009). Despite this interest, comprehensive studies of retinotopic changes following damage to adult central visual pathways are lacking.

Direct damage to visual cortex produces pathology-related deletions of retinotopic maps that can limit the ability to uniquely identify reorganization-induced changes. Consequently, our strategy in this study was to focus on identifying potential "additions" to cortical retinotopic maps. Additions may occur through rerouting or unmasking of visual input. Primary visual cortex of each hemisphere is normally dominated by the representation of the contralateral visual field with a minor representation of the ipsilateral visual field close to the vertical meridian (Tootell et al., 1998). Retinotopic additions of ipsilateral field (IPS) representation have been associated with gross developmental misrouting of retinal input, including the seminal study on albinism (Morland et al., 2001; Hoffmann et al., 2003; Klemen et al., 2012) as well as others in ahemispheric (Muckli et al., 2009) and achiasmatic (Hoffmann et al., 2012) patients, but have not been clearly identified in patients with adult-onset cortical damage.

Here, we capitalized on a unique database of fMRI visual field maps in 45 patients with diverse central brain pathologies (e.g., stroke, tumor, surgically induced pathology) to search for evidence of large-scale plasticity within the visual cortex. Our approach was twofold: (1) to qualitatively characterize the retinotopic organization of the ipsilateral field within visual cortex of each hemisphere; and (2) to quantitatively compare the size of the ipsilateral field representation between patients and healthy subjects. We identified a subset of patients with atypical 
Table 1. Description of Patient Data Sets

\begin{tabular}{|c|c|c|c|c|c|c|}
\hline Patient & Sex & Age (years) & Pathology & $\mathrm{DD}$ & Func Dis & Org type \\
\hline P1 & $\mathrm{F}$ & 37 & Epilepsy, surgical & $Y$ & Y & A \\
\hline P2 & $\mathrm{F}$ & 19 & $\begin{array}{l}\text { Congenital cerebral malformation, } \\
\text { hydrocephalus, epilepsy }\end{array}$ & Y & $\mathrm{N}$ & A \\
\hline P3 & M & 52 & Tumor & Y & $Y$ & A \\
\hline P4 & M & 52 & Tumor, surgical & $Y$ & Y & T \\
\hline P5 & M & 40 & AVM, surgical & Y & Y & $T$ \\
\hline P6 & M & 20 & Tumor & $\mathrm{N}$ & Y & $T$ \\
\hline P7 & M & 56 & Tumor & $\mathrm{N}$ & Y & $T$ \\
\hline P8 & M & 31 & Tumor, surgical & $\mathrm{N}$ & Y & $T$ \\
\hline P9 & $\mathrm{F}$ & 35 & Tumor & $\mathrm{N}$ & $\mathrm{N}$ & $T$ \\
\hline P10 & $\mathrm{F}$ & 51 & Epilepsy, occipital lesion & $Y$ & $\mathrm{~N}$ & $T$ \\
\hline P11 & $\mathrm{F}$ & 65 & Stroke & $Y$ & $\mathrm{~N}$ & $T$ \\
\hline P12 & $\mathrm{F}$ & 46 & Tumor, epilepsy, surgical & $Y$ & $\mathrm{~N}$ & $T$ \\
\hline P13 & M & 50 & Epilepsy, surgical & $\mathrm{N}$ & $\mathrm{N}$ & $T$ \\
\hline P14 & M & 36 & Occipital mass & Y & $\mathrm{N}$ & $T$ \\
\hline P15 & M & 25 & Tumor & $Y$ & $\mathrm{~N}$ & $T$ \\
\hline P16 & M & 23 & Trauma, surgical & $\mathrm{N}$ & $\mathrm{N}$ & $T$ \\
\hline P17 & $\mathrm{F}$ & 64 & Tumor & Y & $\mathrm{N}$ & $T$ \\
\hline P18 & M & 34 & Epilepsy, surgical & $\mathrm{N}$ & $\mathrm{N}$ & $T$ \\
\hline P19 & $\mathrm{F}$ & 48 & Tumor, surgical & Y & $\mathrm{N}$ & $T$ \\
\hline P20 & $\mathrm{F}$ & 36 & Epilepsy, surgical & $\mathrm{N}$ & $\mathrm{N}$ & $T$ \\
\hline P21 & $\mathrm{F}$ & 36 & Epilepsy, surgical & $\mathrm{N}$ & $\mathrm{N}$ & $T$ \\
\hline P22 & $\mathrm{F}$ & 43 & Epilepsy, surgical & $\mathrm{N}$ & $\mathrm{N}$ & $T$ \\
\hline P23 & $\mathrm{F}$ & 45 & Epilepsy, tumor & $Y$ & $\mathrm{~N}$ & $T$ \\
\hline P24 & M & 24 & Stroke & $\mathrm{N}$ & $\mathrm{N}$ & $T$ \\
\hline P25 & $\mathrm{F}$ & 32 & Tumor, surgical & $\mathrm{N}$ & $\mathrm{N}$ & $T$ \\
\hline P26 & M & 42 & Recurrent strokes & $Y$ & $\mathrm{~N}$ & $x$ \\
\hline P27 & $\mathrm{F}$ & 29 & $\begin{array}{l}\text { Congenital cerebral malformation, } \\
\text { hydrocephalus }\end{array}$ & $Y$ & $\mathrm{~N}$ & $x$ \\
\hline
\end{tabular}

F, Female; $M$, male; $N$, no; $Y$, yes; Org type, retinotopic organization type.

organization of visual cortex (areas V1-V3/V3A) consisting of expanded ipsilateral visual field representations compared with healthy subjects. We then considered the possibility that such expansion might be consistent with a competitive model in which damage to visual cortex or the callosal connections removes interhemispheric suppression from retino-geniculate afferents in intact visual cortex that represent the vertical meridian and ipsilateral visual fields.

\section{Materials and Methods}

Subjects. Forty-five patients (age range, 19-65 years; 23 females) with diverse brain pathology and six healthy subjects (age range, 25-48 years; 2 females) participated in this study. Patients with brain pathology that was suspected to involve the visual system were recruited over a period of 6 years by physician referral from hospitals within the Milwaukee Regional Medical Center of Wisconsin. Patients were prescreened and excluded if they (1) had a visual deficit caused by a combination of both retinal and central lesions, (2) were taking either $\alpha$ - or $\beta$-blockers that have a known effect on BOLD imaging, or (3) were unable to remain alert and attentive during the fMRI or perimetry protocols. Pathologic involvement of the visual cortex was confirmed in 27 (of the 45) patients using anatomical and functional MRI data collected within the study. These 27 patients (Table 1) were included for further analysis. Healthy subjects with normal or corrected-to-normal visual acuity were recruited by word of mouth and/or advertising from the student and faculty pool at the Medical College of Wisconsin. Informed consent was obtained from all participants before scanning, in accordance with the procedures and protocols approved by The Medical College of Wisconsin internal review board.

Behavioral data. Visual field perimetry was acquired for patients within $48 \mathrm{~h}$ of fMRI-based visual field mapping. Patients performed either a Humphrey Field Analyzer (HFA) test (10-2 or 30-2) administered by the referring physician or associate or a comparable Video Automated Perimetry (VAP) test (10-2 or 30-2) custom designed for the
MRI environment and administered by the experimenter. As a result of the different types of visual field perimetry acquired, patients were tested either binocularly or monocularly. Binocular testing produced one visual sensitivity plot that represents the contribution of both eyes together. Monocular testing produced two separate visual sensitivity plots, each of which represents the contribution from one eye.

Retinal imaging and fixation tracking were performed with two patients having atypical retinotopic organization [patient 1 (P1) and P2] using an OPKO combined scanning laser ophthalmoscope (SLO) with optical coherence tomography (OCT) (Sabates et al., 2011). This follow-up study occurred 5 and 1.5 years after the initial fMRI study of P1 and P2, respectively. For each eye, patients were instructed to fixate a central crosshair and perform an HFA 10-2 (or HFA modified 10-2) equivalent perimetry task while the OPKO tracked fixation on the retina. The OPKO SLO is an internal fixation tracking device that uses a retinal landmark selected from the SLO fundus image (typically, prominent blood vessels), and continuous image capture with the SLO throughout the microperimetry examination to track eye movements and accurately place the stimulus in the same location for each presentation. Such internal fixation tracking devices have been shown to provide high repeatability and agreement in fixation stability assessment during microperimetry (Chen et al., 2011). The resulting data include a plot of fixation points on the SLO retinal image aligned with the OCT retinal images from which the following were calculated: (1) the centroid of fixation excluding points beyond $2^{\circ}$ that appeared to be saccadic, (2) the mean distance and (3) SE of fixation points from the centroid, and (4) the distance between the centroid of fixation and the center of the foveal pit identified by OCT.

MRI acquisition and postprocessing. Anatomical and functional MRI data were acquired on one of two MRI scanners: a General Electric Signa 3 tesla scanner with an in vivo 8-channel head coil ( $n=22$ patients, 6 healthy subjects), or a General Electric Signa 1.5 tesla scanner with an IGC Medical Advances mirrored bird cage head coil ( $n=5$ patients). Anatomical, T1-weighted, 3D-spoiled, gradient-recalled-at-steady-state images were acquired for the whole brain in the axial direction at a resolution of $0.96 \times 1.07 \times 1.00 \mathrm{~mm}$ [repetition time (TR) $9.5 \mathrm{~ms}$; echo time (TE), $3.9 \mathrm{~ms}$; flip angle, $12^{\circ}$ ]. Functional T2*-weighted gradientrecalled, echoplanar images were acquired in the axial plane at a resolution of $3.75 \times 3.75 \times 4.00 \mathrm{~mm}$ (for $3 \mathrm{~T}$ : TR, $2000 \mathrm{~ms}$; TE, $30 \mathrm{~ms}$; flip angle, $77^{\circ}$; for $1.5 \mathrm{~T}$ : TR, $2000 \mathrm{~ms}$; TE, $40 \mathrm{~ms}$; flip angle, $90^{\circ}$ ). Each functional scan was either 108 time frames $(2 \mathrm{~s}$ TR) in duration, of which the first 6 and last 2 time frames ( $16 \mathrm{~s}$ ) were discarded, or 84 time frames $(2 \mathrm{~s})$ in duration, of which the first 2 and last 2 time frames (8s) were discarded. A total of six repeated scans (three scans for each of two tasks) were acquired within the same session for each subject.

fMRI postprocessing was performed with the AFNI analysis suite (Cox, 1996). Raw fMRI k-space data were converted to images using a custom reconstruction technique (Jesmanowicz et al., 1998). The resulting images were assembled into volumetric datasets, coregistered to reduce motion artifacts. Data from repeated stimulus tasks were then averaged across scans. For qualitative analyses only (i.e., visual display and visual area boundary identification), spatial smoothing was performed on the task-averaged time series data using a $6 \mathrm{~mm}$ spherical function.

Visual stimuli and identification of active voxels. As described previously (DeYoe et al., 2011), conventional eccentricity and polar angle mapping were accomplished using temporal phase-mapped, counterphase flickering ( $8 \mathrm{~Hz}$ ) checkered annuli and wedges (Engel et al., 1994, 1997; Sereno et al., 1995; DeYoe et al., 1996). Briefly, an annulus expanded from the center of gaze to the periphery over a period of 32 or $40 \mathrm{~s}$. The expansion steps, inner and outer diameters, and check size were all scaled in proportion to the mean eccentricity of the annulus. A wedge (quarter or hemifield) rotated about the center of gaze over a period of 32 or $40 \mathrm{~s}$. The annulus expansion or wedge rotation sequences were repeated five times in succession during each $\mathrm{fMRI}$ scan. Participants were instructed to fixate on a central green square and not move their eyes or head while viewing the stimulus sequences. Stimuli were viewed using either binocular stalks ( $\sim 9^{\circ}$ viewing angle depending on optical focus) with an Avotec Silent Vision Visual System or a custom mirror and 

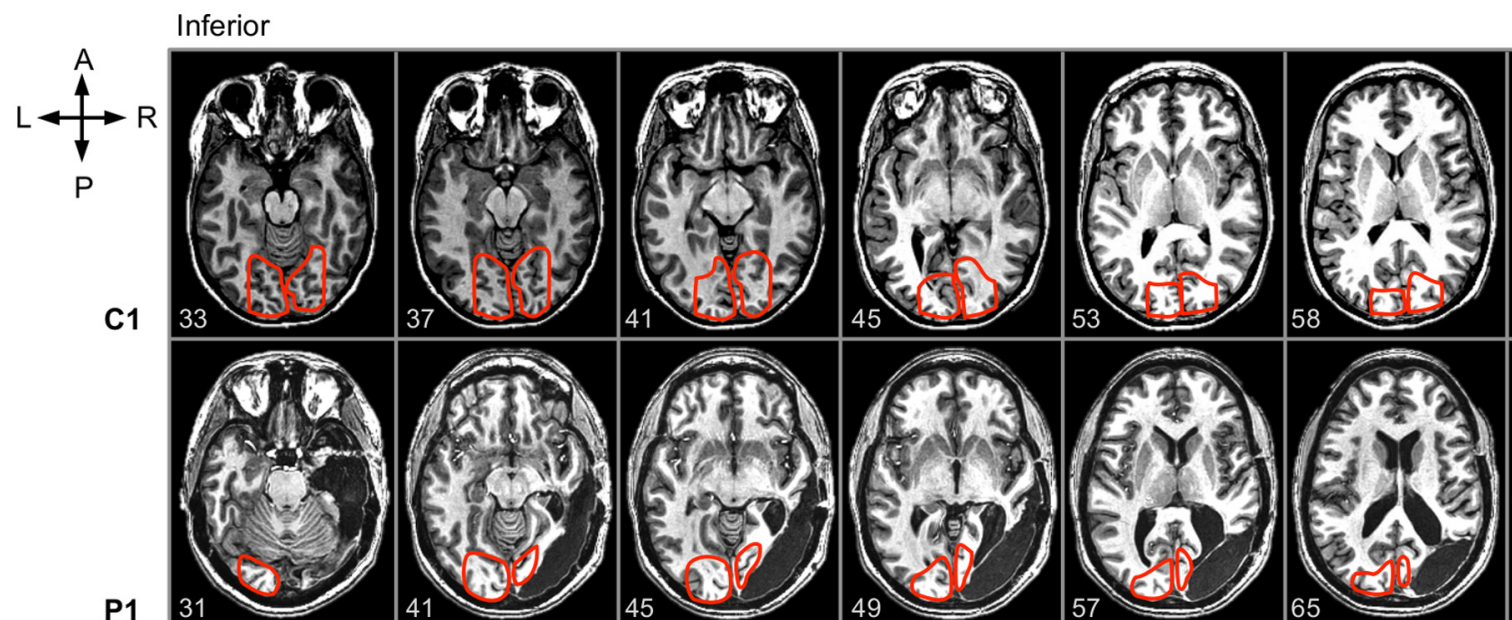

Superior

$\mathbf{P 1}$
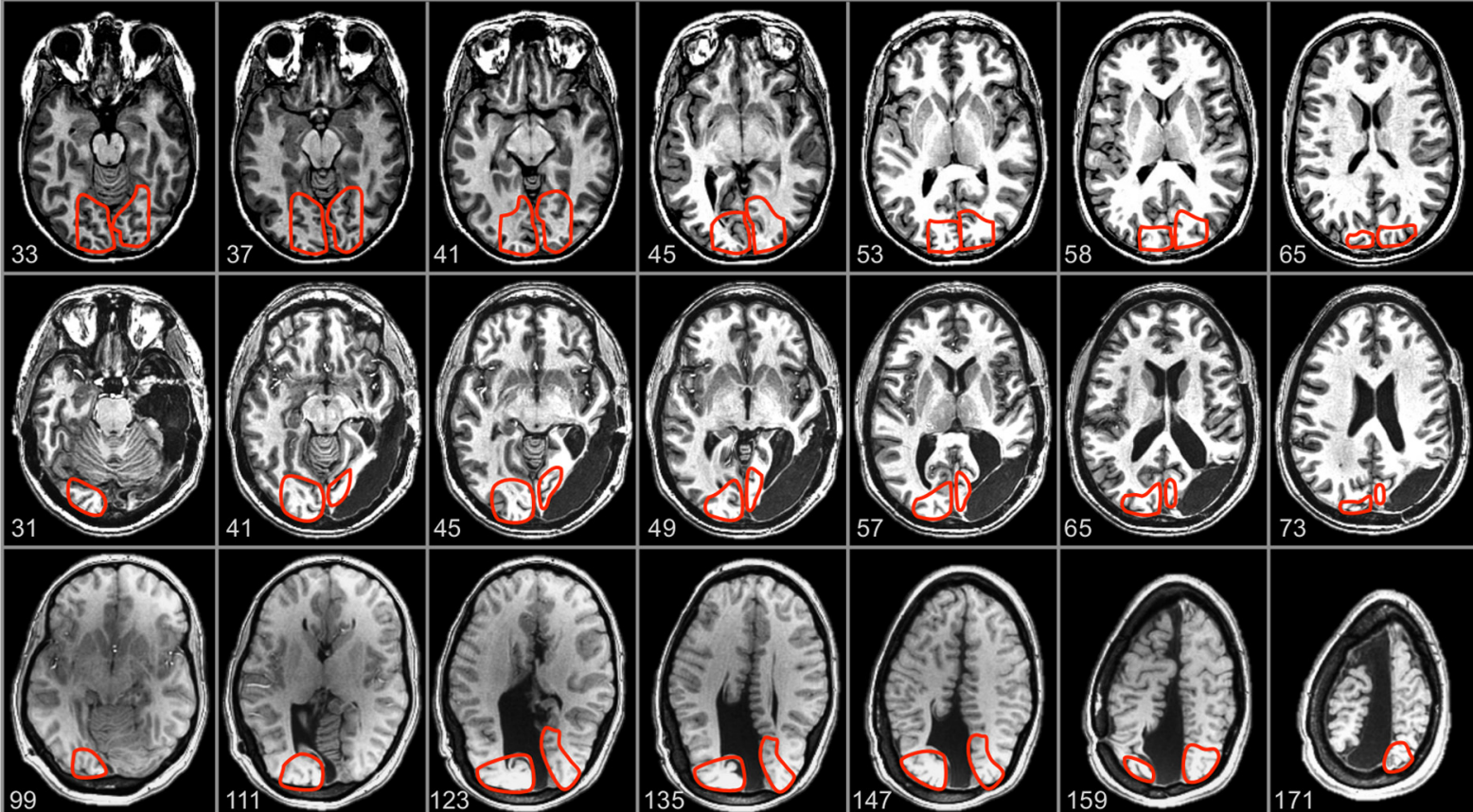

P2
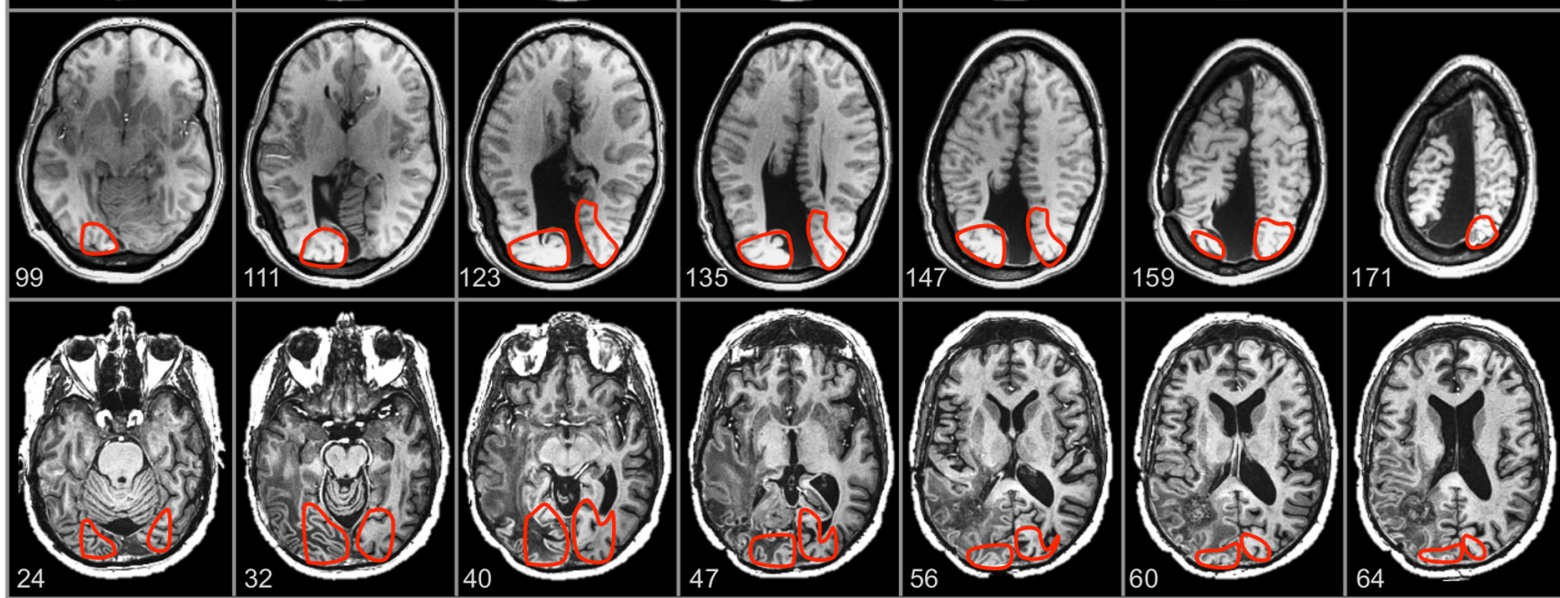

Figure 1. Anatomy and analysis V0Is for $\mathrm{C} 1$ and patients with atypical ipsilateral field representation (P1-P3). The most inferior slices are depicted on the left, and progressively more superior slices are depicted on the right. Slice number is indicated in the lower left corner of each image. Cortical tissue included in the VOls of each hemisphere is outlined in red. L, Left; $R$, right; $A$, anterior; P, posterior.

back-projection screen mounted on the MR head coil $\left(\sim 21^{\circ}\right.$ viewing angle depending on head size/positioning) with images projected by an Avotec SV-6011 Projection Visual System or Brain Logics MR Digital Projection System. Either a Cambridge Research \& Instrumentation VSG video board or custom Prism Acquire software (http://www.prismclinical.com) drove the projection systems.

The retinal position of the stimulus that optimally activated a particular cortical locus (voxel) was determined from the time delay of its fMRI response using the Hilbert Delay "plug-in" of the AFNI (Analysis of Functional NeuroImages) software package (Cox, 1996). To identify valid fMRI responses, the algorithm used a modification of a standard temporal cross-correlation method using a sinusoidal reference waveform (Bandettini et al., 1993; Saad et al., 2003), and efficiently identified the optimum temporal phase, the cross-correlation coefficient, and the covariance for each voxel. Active voxels were defined as those with a correlation coefficient $\geq 0.40$. The statistical significance of each active voxel within a volume of interest (VOI) was computed automatically within AFNI and corrected for multiple comparisons using the false discovery rate $q$ value. At a correlation coefficient of 0.40 , the mean $q$ value in our subjects was 0.0016 (SEM, \pm 00034 ).

Visual cortex volume of interest. Prism View visualization and analysis software (http://www.prismclinical.com) was used to construct VOIs that generally included visual areas V1-V3. Three-dimensional VOIs were constructed on the task-averaged (nonsmoothed) functional data slice by slice using the anatomical data to define the VOI boundaries (Fig. 1). The VOIs were constrained by the medial, ventral, and posterior edges of occipital cortex, and the lateral ventricles and collateral sulcus. To avoid fMRI noise artifacts typically thought to be due to flow effects in venous structures along the parietal occipital sulcus (POS) and midsag- ittal sinus, VOIs followed the white/gray matter boundary or up to one to two voxels away from the POS in clear cases of drainage artifacts. To confirm that the VOIs accurately included V1-V3 and excluded higher visual areas, we later overlaid the masked datasets onto cortical surface models for two healthy subjects and five patients, and identified visual area boundaries based on retinotopic features (see Cortical surface model construction and visual area identification). Note that two main factors prevented the construction of VOIs based solely on visual area boundaries: (1) the required cortical surface models could not be constructed in many patient hemispheres due to extensive damage; and (2) some patient hemispheres with cortical surface models had insufficient retinotopy to identify visual area boundaries.

Functional field maps. We computationally "back-projected" the cortical fMRI activation patterns onto a chart of the observer's visual field. The resulting display, termed a "functional field map" (FFMap) shows which portions of the subject's visual field are capable of evoking a brain response. Individual FFMaps were constructed from all voxels within or intersecting the VOI mask (see above) that were active in both the eccentricity and polar angle tasks. The task-averaged data were used to determine the visual field location (eccentricity and polar angle) of the stimulus that maximally excited each visually responsive voxel within the VOI. For each active voxel, a circle symbol was computationally placed at the corresponding location on a schematic diagram of the visual field. The color of the symbol was selected from a scale representing the polar angle location in the visual field for that voxel. The diameter of each symbol was scaled to a $70 \%$ confidence interval for the true visual field location, based on a previous study by Saad et al. (2001) in which the temporal variability of fMRI responses was characterized. In that study, the SD in temporal phase delay across all responsive voxels in a sample 
A

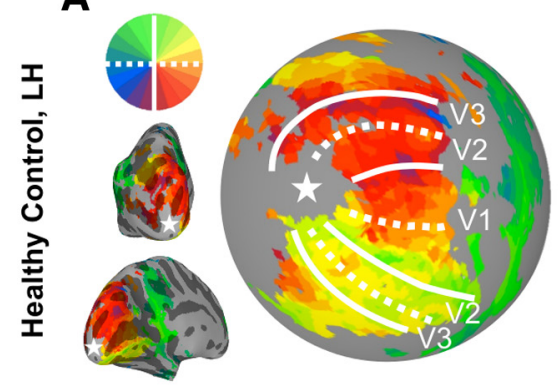

E

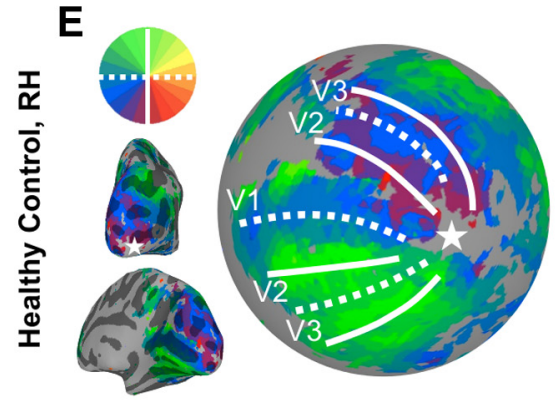

B

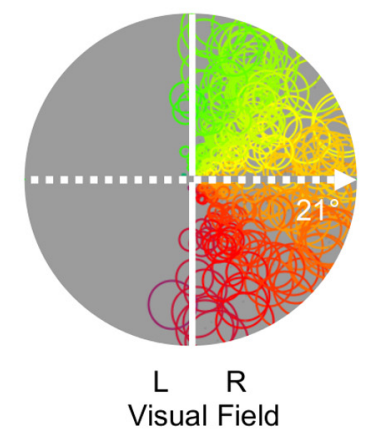

F

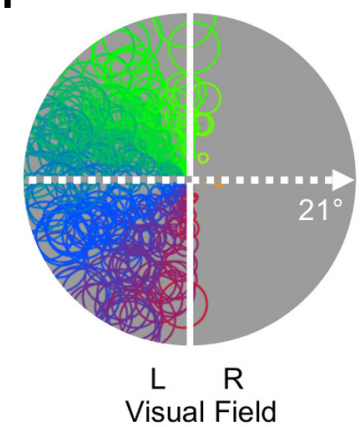

C

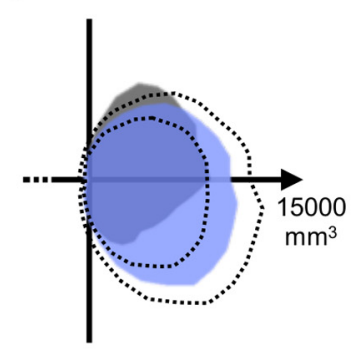

L $\quad \mathrm{R} \quad$ Individual

Visual Field Controls

G

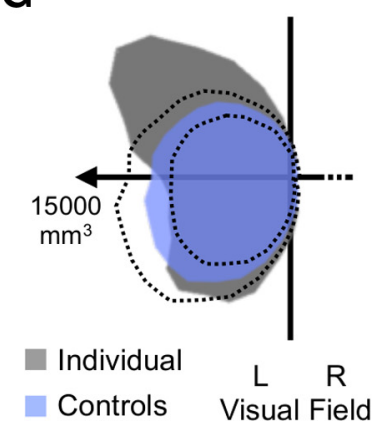

D

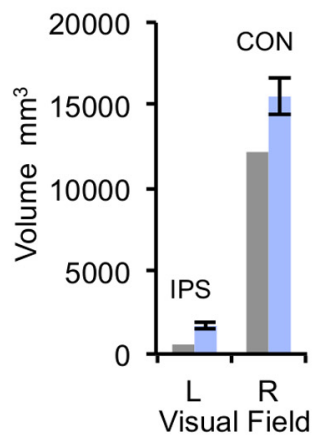

H

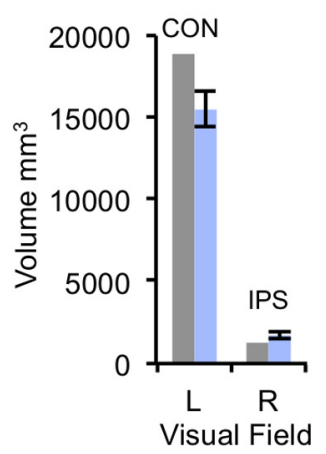

Figure 2. Polar angle retinotopy for $(1 . \boldsymbol{A}, \boldsymbol{E}$, Color-coded polar angle maps from the left $(\boldsymbol{A})$ and right $(\boldsymbol{E})$ hemispheres displayed on partially inflated (left) and spherical (right) cortical surface models (posterior pole: white star). Visual area boundaries are marked by representations of the horizontal (dotted white) and vertical (solid white) meridian representations. $\boldsymbol{B}, \boldsymbol{F}$, Functional field maps depicting a back-projection of the retinotopic maps from the left $(\boldsymbol{B})$ and right $(\boldsymbol{F})$ hemispheres onto maps of $(1$ 's visual field. Each circle in the FFMap is associated with a voxel in the brain that was maximally activated by a stimulus at the symbol's location in the visual field. The color of the symbols is as for $\boldsymbol{A}$ and $\boldsymbol{E}$. C, G, Polar histograms depicting the amount (in cubic millimeters) of brain tissue (voxels) in the left $(\boldsymbol{C})$ and right $(\boldsymbol{G})$ hemispheres representing different angular positions in the visual field of $\mathrm{C}$ (gray shading) and averaged for all healthy controls (light blue shading, dotted lines show \pm SEM). $\boldsymbol{D}, \boldsymbol{H}$, Bar graphs depicting the total amount of tissue representing each visual hemifield in the left $(\boldsymbol{D})$ and right $(\boldsymbol{H})$ hemispheres of $\mathrm{C} 1$ (gray shading) and averaged for all healthy controls (light blue shading; error bars indicate \pm SEM). L, Left; R, right; RH, right hemisphere; LH, left hemisphere.

from seven subjects was found to be $2.1 \mathrm{~s}$. For a temporal phase-mapping paradigm with a $40 \mathrm{~s}$ cycle period, the $70 \%$ confidence interval for the estimated phase delay is thus $2.16 \mathrm{~s}$. The diameter of the circle symbol was then adjusted accordingly to reflect the corresponding range in mean eccentricity of the annulus mapping sequence. (Note that the range scales with eccentricity so that the symbols are smaller near the center of gaze. Accuracy in the polar angle dimension also scales with eccentricity, so for simplicity the symbols have been plotted as circles. We also assume that the variance of fMRI phase measurements is approximately uniform throughout visually responsive cortex.)

Histograms and statistical analyses. Polar histograms were created to show the volume of cortical tissue responding to each polar angle increment within the observer's visual field. Using a sliding boxcar window (width, $45^{\circ}$; step size, $9^{\circ}$ ), individual polar histograms were constructed for each hemisphere separately from all voxels in the VOI mask that were activated by the polar angle task. Bar histograms were created by binning the total volume of cortex responding to the left and right hemifields. Each mean and its SE were computed. In healthy subjects, two-sided Wilcoxon rank sum tests were used to test the hypothesis of no difference in the distributions of the volume of cortex activated by each hemifield between the left $(n=6)$ and right $(n=6)$ hemispheres. No significant difference was found in the ipsilateral hemifield between the left (1568 \pm $\left.235 \mathrm{~mm}^{3}\right)$ and right $\left(1428 \pm 250 \mathrm{~mm}^{3}\right)$ hemispheres (test statistic, $W=$ $42, p=0.6905)$ or in the contralateral hemifield between the left $\left(14,661 \pm 1996 \mathrm{~mm}^{3}\right)$ and right $\left(15,447 \pm 970 \mathrm{~mm}^{3}\right)$ hemispheres $(W=$ $32, p=0.3095)$. Thus, to obtain the best estimate of the normal amount of ipsilateral and contralateral field (CON) representation in any given hemisphere, regardless of side, we averaged the histograms of each healthy subject after "flipping" the right hemisphere histograms $180^{\circ}$ across the vertical meridian. The resulting group-averaged histogram displays the ipsilateral field on the left and the contralateral field on the right. For comparison, group-averaged histograms for patient hemi- spheres with typical and atypical organization were produced in the same manner. To test for between-group differences in the distributions of the volume of cortex activated by each hemifield, we performed two-tailed Wilcoxon rank sum tests using the Matlab statistics toolbox (http://www.mathworks.com/help/stats/ranksum.html).

Cortical surface model construction and visual area identification. Smoothed, task-averaged functional data were projected onto cortical surface models for five patients with retinotopic anomalies (three shown) and two healthy controls (one shown) using public domain software packages SureFit and Caret (http://brainmap.wustl.edu; Van Essen et al., 2001) or Freesurfer (http://surfer.nmr.mgh.harvard.edu). The smoothed surface maps were only used qualitatively for visual display and identification of visual areas to emphasize global patterns of topography. Visual areas were determined by manual identification of sign reversals in the representation of visual field polar angle. All quantitative analyses were performed on the unmodified (nonsmoothed) task-averaged volumetric data.

\section{Results}

Retinotopic maps in healthy subjects primarily represent the contralateral field

As a control condition, we performed fMRI-based visual field mapping in six healthy subjects to characterize the normal ipsilateral field representation. Figure 2 summarizes our findings for a representative healthy control subject $(\mathrm{C} 1)$. Voxels that were activated by a rotating checkered wedge stimulus are color coded to show their preferred stimulus polar angle and displayed as an overlay on spherically inflated cortical surface models of each hemisphere (Fig. 2A,E). Both hemispheres were primarily activated by stimuli in the contralateral (opposite) visual hemifield but also had a small amount of activation extending along the 

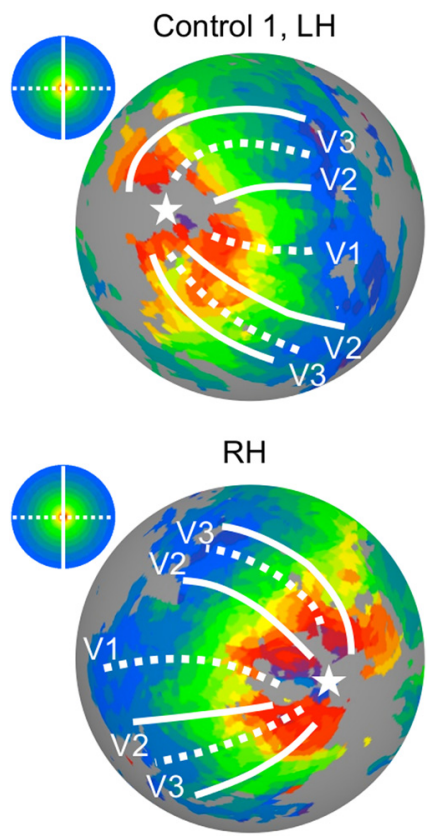

Figure 3. Eccentricity maps for healthy control (C1). Color-coded eccentricity maps from the left (top) and right (bottom) hemispheres of $(1$ displayed on spherical cortical surface models (posterior pole: white star). Visual area boundaries are as in Figure 2, $A$ and E. RH, Right hemisphere; LH, left hemisphere.

vertical meridian into the ipsilateral (same-side) field. For instance, the left hemisphere (Fig. 2A) contained representations of the right visual field (red-oranges, yellow-greens) and the vertical meridian (white solid lines) with a very small representation of the ipsilateral field (blue-purples and darker greens). Notably, the ipsilateral field representation can be difficult to detect within visual areas V1-V3. Since spatial and temporal "smoothing" during common postprocessing methods may contribute to this effect, smoothed flat maps are only used here for display purposes, and all quantitative analyses (see below) were based on the unsmoothed $3 \mathrm{D}$ volumetric data. As an analysis tool, the normally small size of the ipsilateral field representation within healthy subjects enables any additions within patients to be particularly apparent.

Retinotopic maps for this same subject showing voxels activated by the expanding ring stimuli and color coded by visual field eccentricity are depicted as an overlay on spherically inflated cortical surface models in Figure 3. Note the mirror symmetric representations of visual field eccentricity between hemispheres and the large cortical magnification of the center of gaze (reds, oranges) near the occipital pole (white star) compared with more peripheral eccentricities (greens, blues). To visualize relationships between the cortical retinotopic maps and the subject's visual field, we used the polar angle and eccentricity data to backproject the retinotopic maps from each hemisphere onto a map of the subject's visual field, as illustrated in Figure 2, B and F. Each circle symbol has a one-to-one relationship with a voxel in the early visual cortex VOI (Fig. 1, red outline, row C1) that was activated by both the rotating wedge and expanding ring stimuli. In correspondence with Figure 2, $A$ and $E$, symbols are color coded by visual field polar angle. As expected, the resulting functional field maps showed a full representation of the contralateral visual field (within the tested eccentricities) in each hemisphere. The ipsilateral field locations that maximally activated voxels in visual cortex were also apparent. For instance, the left hemisphere functional field map (Fig. 2B) contained a fairly uniform distribution of symbols mostly restricted to the right side of the map and a small number of symbols extending into the ipsilateral field along the vertical meridian. Note that the diameter of each symbol reflects a $70 \%$ confidence interval for the true visual field location and are not an estimate of population receptive field size.

To quantify the ipsilateral representation and its range of variability within healthy subjects, we converted the functional field maps into polar histograms that show the amount (in cubic millimeters) of brain tissue (voxels) representing different angular positions in the subject's visual field (Fig. $2 C, G$ ). The majority of early visual cortex in each hemisphere of $\mathrm{C} 1$ (Fig. $2 C, G$, gray shading) and the control group as a whole (Fig. $2 C, G$, light blue shading) was devoted to representation of the contralateral field, but a small amount of tissue was devoted to the ipsilateral field, particularly near the vertical meridian. Not only was the amount of activation in the contralateral field larger than in the ipsilateral field, but the variability also was larger (Fig. 2C,G, black dashed lines: \pm SEM). Note that, to create the average polar histogram for control subjects (Fig. 2C,G, light blue shading), data were pooled from both hemispheres after "flipping" the field representation of one hemisphere. The same average histogram is shown in Figure 2, $C$ and $G$, but is "mirrored" across the vertical meridian. The total amount of activation for each visual hemifield was summed and displayed as a bar graph (Fig. $2 D, H$ ). On average for the control group, $10 \%$ of the tissue in the early visual cortex VOIs represented the ipsilateral field $\left(1519 \pm 165 \mathrm{~mm}^{3}\right)$ compared with the contralateral field $\left(15,075 \pm 1065 \mathrm{~mm}^{3}\right)$.

\section{Patients had diverse central pathologies, ages of onset, and retinotopic maps}

From an initial dataset of 45 patients with brain pathology, 27 patients were selected with clear anatomical evidence of pathology involving visual cortex and/or underlying white matter tracts. As detailed in Table 1, 2 patients (P2, P27) had congenital cerebral malformations, and the remaining 25 patients had adultonset pathologies including the following: arteriovenous malformation (AVM), epilepsy, stroke, tumor, trauma, and surgically induced collateral damage. The pathology resulted in direct damage to visual cortex within the VOI (generally V1-V3) in 15 patients [Table 1 , direct damage $(\mathrm{DD})=$ yes]. The involved hemisphere was functionally "disconnected" from the opposite hemisphere (e.g., it was mostly nonfunctional or had a developmental absence of a corpus callosum) in seven patients [Table 1, functional disconnection (Func Dis) = yes]. The mean patient age at the time of study was 39.7 years ( $\mathrm{SD}=12.6$ years). The time between the onset of pathology (for known cases, $n=8$ ) and the time of study ranged from 0.5 to 25 years (mean $=8.3$ years, $\mathrm{SD}=8.2$ years $)$

Using the same fMRI-based analyses in patients as those used for the healthy control subjects (see above), the retinotopic organization of visual cortex was examined in all 27 patients for gross evidence of anomalies in the ipsilateral field representation. Initial screening was based on a manual, qualitative inspection of retinotopically encoded fMRI activation within each hemisphere of each patient independently. Briefly, we observed three different retinotopic outcomes in patients: (1) 3 patients had atypical [Table 1, atypical (type A)] retinotopic organization consisting of an expanded ipsilateral field representation compared with healthy controls; (2) another 22 patients had typical (type $\mathrm{T}$ ) retinotopic organization compared with healthy subjects, except for the presence of retinotopic deletions related to their pathologies; and (3) the 2 
A
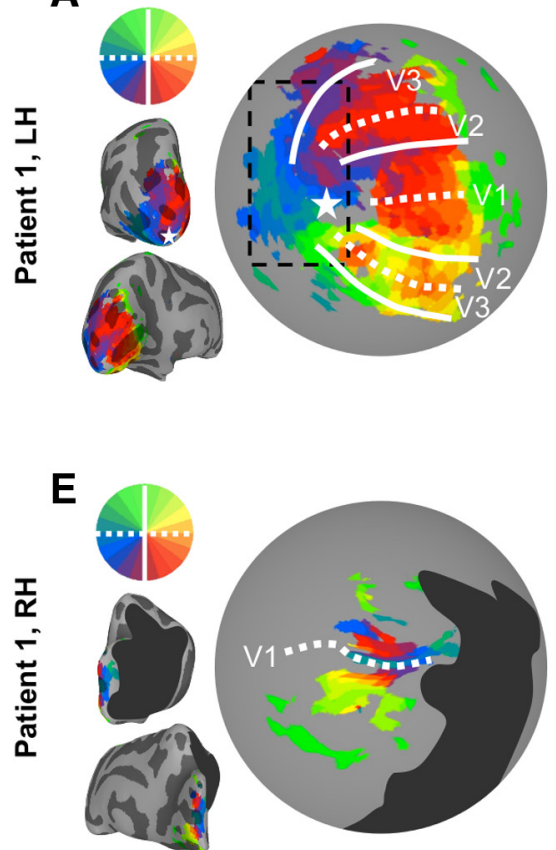

B

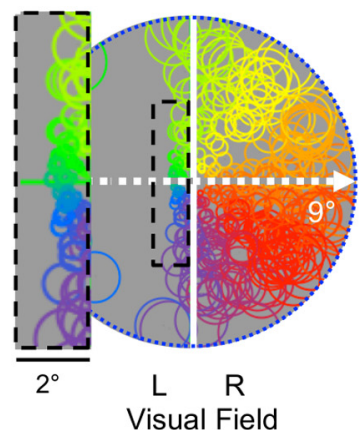

F

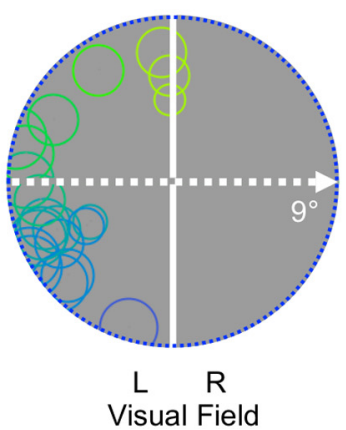

C

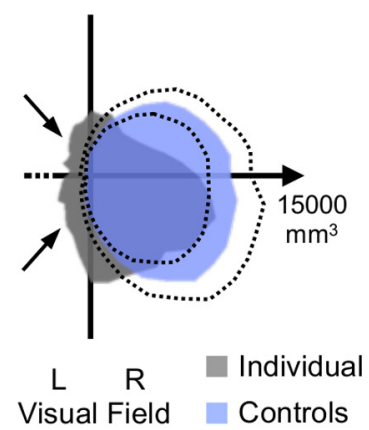

G

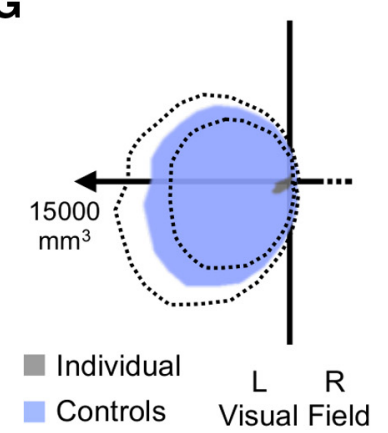

D

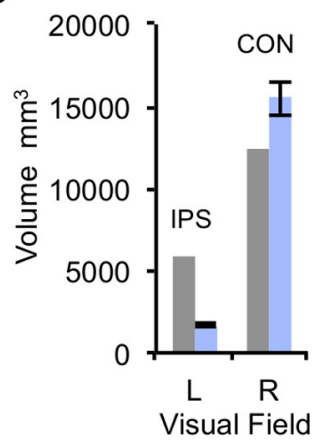

H

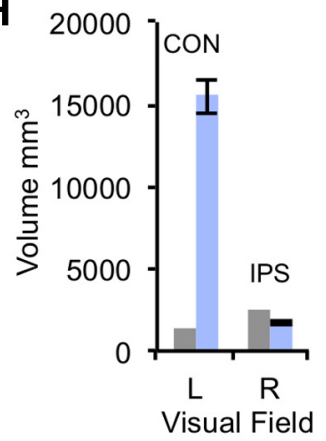

Figure 4. Polar angle retinotopy for patient with surgical ablation of epileptic focus in right hemisphere (P1). $\boldsymbol{A}-\boldsymbol{H}$, Figure layout is the same as in Figure 2, with the following exceptions. $\boldsymbol{A}$, Black dashed outlines indicate approximate location of expanded ipsilateral representation. $\boldsymbol{B}$, Black dashed outlines highlight inset showing expanded ipsilateral representation especially near fovea. $\boldsymbol{B}$, $\boldsymbol{F}$, Blue dashed outlines encircle the regions corresponding with the visual field perimetry in Figure $5 B$. $\boldsymbol{E}$, Dark shading indicates regions of brain damage. Location of $\mathrm{V} 1$ in the right hemisphere was estimated by fundus of calcarine sulcus. RH, Right hemisphere; $\mathrm{LH}$, left hemisphere.

remaining patients had evidence for pathology-related hemodynamic artifacts (type $\mathrm{X}$ ) in their retinotopic maps, defined as BOLD activation that was not reflective of the underlying neural network, and were subsequently removed from further analysis. Both of the latter patients had pathology affecting the normal hemodynamics within visual cortex and, unlike type A patients, had clusters of topographically inconsistent fMRI activation in these regions of cortex that were equally affected in the eccentricity and polar angle task data (i.e., the delay values of voxels in each task were offset by the same amount).

\section{A subset of patients with central damage had an expanded ipsilateral field representation}

Patient 1: surgically induced collateral damage

P1 was a 37-year-old female with epileptic foci. She underwent a temporal-occipital resection of the right hemisphere including partial resection of the optic radiations (Fig. 1, void, row P1). Only a portion of medial visual cortex remained intact within the right hemisphere (Fig. 4E, black patch depicts damaged brain region) and was primarily activated by regions of the contralateral field (Fig. $4 F$, greens, cyans, blues) at peripheral eccentricities (Fig. 5A, bottom row). (Note that the reds and yellows on the cortical surface model in Fig. $4 E$ appear to be a partial volume effect from the opposite hemisphere and were eliminated by the VOI mask used for the FFMaps and quantitative analysis). The FFMap in Figure 4F, a back-projection of the visual activation in the right hemisphere, corresponds to the central $9^{\circ}$ of visual field perimetry in Figure $5 B$ (blue dotted outline). The FFMap symbols correspond to regions of the visual field in which the patient's behavioral sensitivity to points of flashed light was degraded or absent (Fig. 5B, black patches in left hemifield). Given the extensive damage to the right hemisphere, visual acti-
A
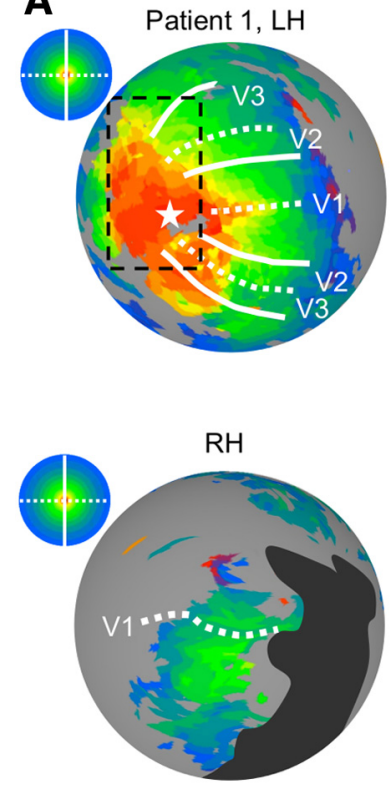

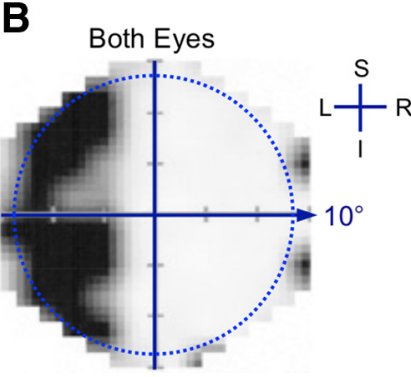

Relative Visual Sensitivity $0 \longleftarrow 1$
Figure 5. Eccentricity maps and perimetry for P1. A, Figure panel layout is the same as in Figure 3, except that the black dashed outline and visual area boundaries are as in Figure $4 A, E$. $B$, VAP 10-2 test (based on the Humphrey 10-2 perimetry) performed binocularly (both eyes together). Gray scale indicates the relative visual sensitivity from 0 to 1 . Blue dashed outline encircles the region corresponding with the FFMaps in Figure 4, $B$ and $F$. L, Left field; $R$, right field; S, superior field; I, inferior field; RH, right hemisphere; LH, left hemisphere.

vation may have been disconnected from behavioral awareness at higher stages in the visual pathway. Quantitatively, the amount of visual activation within this hemisphere was minute (Fig. 4G, $H$, gray shading) compared with normal controls (Fig. 4G,H, light 
blue shading), reflecting the effects of direct damage to that hemisphere.

This patient's left hemisphere was anatomically intact and contained a retinotopic map of the contralateral field (Fig. $4 \mathrm{~A}$, magentas, red-oranges, yellow-greens), but with the addition of an atypical ipsilateral field representation (purples, blues, and greens, highlighted by black dashed outline) involving the central visual field (Fig. 5A, top, reds, oranges, yellows). The atypical representation extended $\sim 1.5^{\circ}$ into the left visual field along the vertical meridian (Fig. $4 B$ ) and corresponds to the patient's remaining behavioral sensitivity in the left hemifield near the visual midline (Fig. $5 B$, white strip). While the right hemisphere would normally support this region, we noted above that this patient's damaged right hemisphere did not contain a significant representation of this portion of the visual field (Fig. $4 F$ ). Quantitatively, the left hemisphere had a markedly larger representation of the ipsilateral (left) hemifield compared with healthy controls (Fig. $4 C, D$, left field, gray vs blue: 5850 vs $1519 \pm 165 \mathrm{~mm}^{3}$ ). Moreover, this larger ipsilateral field representation was accompanied by a smaller contralateral (right) field representation relative to controls (Fig. $4 C, D$, right field, gray vs blue: 12,488 vs $15,075 \pm$ $1065 \mathrm{~mm}^{3}$ ), even though this hemisphere was anatomically intact.

\section{Patient 2: congenital cerebral malformation}

P2 was a 19-year-old acallosal female with congenital cerebral malformation and chronic epilepsy. Both parietal and occipital lobes were hypergyrated and malformed around a central expanded ventricle/void (Fig. 1, row P2). In the right hemisphere, despite the grossly distorted cortical surface, the topography of the polar angle (Fig. $6 E$ ) and eccentricity (Fig. 7A, bottom row) remained largely intact and comparable to that in healthy subjects. Typical sign reversals in the polar angle representation allowed the delineation of dorsal visual areas V1-V3 and ventral visual areas V1-V2 (Fig. 6E), which together contained a representation of the entire contralateral (left) hemifield (Fig. 6F). Quantitatively, the relative distribution of activation across angular locations in the visual field (Fig. 6G) was comparable to controls, though the total amount of visual activation was smaller (Fig. $6 \mathrm{H}$, gray vs blue). This difference in total volume may reflect an overall reduction in occipital cortical tissue as a result of the cerebral malformation.

In contrast to the right hemisphere, the left hemisphere of P2 contained gross distortions of both the cortical surface (Fig. 1, row P2) and the retinotopic organization in the polar angle maps (Fig. 6A, black dashed outline). Only visual areas V1 and ventral $\mathrm{V} 2-\mathrm{V} 3$ could be estimated from sign reversals in the contralateral (right) visual field representation. In healthy individuals, the dorsal V1/V2 boundary is typically associated with a field sign reversal and a progression within V2 back toward the horizontal meridian (Fig. 2A). However, in P2, the map does not change sign but progresses (counterclockwise in Fig. 2) through an expanded representation of the lower right quadrant (red-oranges) with a seamless transition into the left hemifield inferior quadrant (purples, blues) and then into the left superior quadrant (cyans, greens). This atypical, yet coherent progression thus constitutes a complete, ordered transit through both hemifields. However, the ipsilateral representation was primarily associated with central eccentricities (Fig. 7A, black dashed outline). In the FFMap (Fig. $6 B$, black dashed outline), this appears as symbols populating the left central field except near the vertical meridian, where it expanded more peripherally. Since these visual field regions were also represented in the right hemisphere (Fig. 6, compare B, F), we were not able to determine unequivocally whether the atypical representation was contributing to the patient's visual sensitivity to these regions during microperimetry testing, as shown in Figure $7 B$ by the green dots in the left hemifield that are superimposed onto images of the retina of this patient. (The microperimetry in Fig. $7 B$ corresponds to the central $7^{\circ}$ of the FFMaps in Fig. 6 B, F, indicated by the blue dotted outline. Retinal images are shown for the left and right eyes, tested separately, and have been oriented to reflect visual field space, as is typically done for conventional perimetry displays.) Quantitatively, the amount of ipsilateral (left) field activation in the left hemisphere was larger than observed in healthy controls (Fig. 6C,D, left field, gray vs blue: 3881 vs $1519 \pm 165 \mathrm{~mm}^{3}$ ). As in the first patient, the enlarged representation of the ipsilateral field in this hemisphere was accompanied by a smaller representation of the contralateral field (Fig. $6 C, D$, right field, gray vs blue: 7256 vs $15,075 \pm 1065$ $\mathrm{mm}^{3}$ ).

\section{Patient 3: brain tumor}

Figure 8 summarizes the results for P3, a 52-year-old male with an anaplastic astrocytoma and compromised tissue in the left occipital, parietal, and temporal lobes (Figs. 1, row P3, 8A, white dashed outline). Since the extensive cortical damage prevented construction of a cortical surface model for the left hemisphere, anatomical MR images showing three views are displayed instead. The fMRI overlay is color coded by the visual field polar angle (Fig. 8A). A small region of cortex in the left hemisphere (Fig. $8 \mathrm{~A}$, green crosshairs) was activated appropriately by stimuli in the upper right visual quadrant between $12^{\circ}$ and $21^{\circ}$ in eccentricity (Fig. $8 B$ ). But, the patient responded unreliably to stimuli in this quadrant during perimetry testing (Fig. 9B). (The FFMap in Fig. $8 B$ corresponds to the central $21^{\circ}$ of the perimetry from Fig. $9 B, F$, as indicated by the blue dotted outlines. Perimetry is shown for the left and right eyes tested separately.) Quantitatively, the amount of visual activation within the left hemisphere was minute compared with normal controls (Fig. $8 C, D$, gray vs blue).

The right hemisphere of this patient was anatomically intact and contained a full retinotopic map of the contralateral field (Fig. 8E, purples, blues, greens) but with an apparently expanded representation of the ipsilateral field (Fig. $8 E$, reds, oranges). In contrast to P1 and P2, the ipsilateral field expansion appeared integrated within the normal vertical meridian representations of the contralateral field, rather than as a topographically displaced (ectopic) zone. This is perhaps more evident in the functional field map (Fig. $8 F$ ), which shows the expanded ipsilateral representation extending from the center of gaze to approximately $10^{\circ}$ eccentricity in the lower right quadrant (black dashed outline) and clustered between $8^{\circ}$ and $21^{\circ}$ in eccentricity in the upper right quadrant. As already noted, the patient did not respond reliably to points of light flashed in the right visual field, though some degraded visual sensitivity may have remained (Fig. 9B, white patches in right hemifield). Quantitatively, the contralateral (left) visual field representation in the right hemisphere was comparable to healthy controls (Fig. 8G,H, left field, gray vs blue: 15,694 vs $15,075 \pm 1065 \mathrm{~mm}^{3}$ ), but the ipsilateral (right) field representation was markedly larger than controls (Fig. $8 G, H$, right field, gray vs blue: 4838 vs $1519 \pm 165 \mathrm{~mm}^{3}$ ).

\section{Group-level analysis}

We performed a quantitative, group-level analysis of the ipsilateral field representation to test the significance of the atypical organization in hemispheres from patients $\mathrm{P} 1-\mathrm{P} 3$ compared with healthy subjects (Fig. 10A, B, IPS, red vs light blue shading). On 

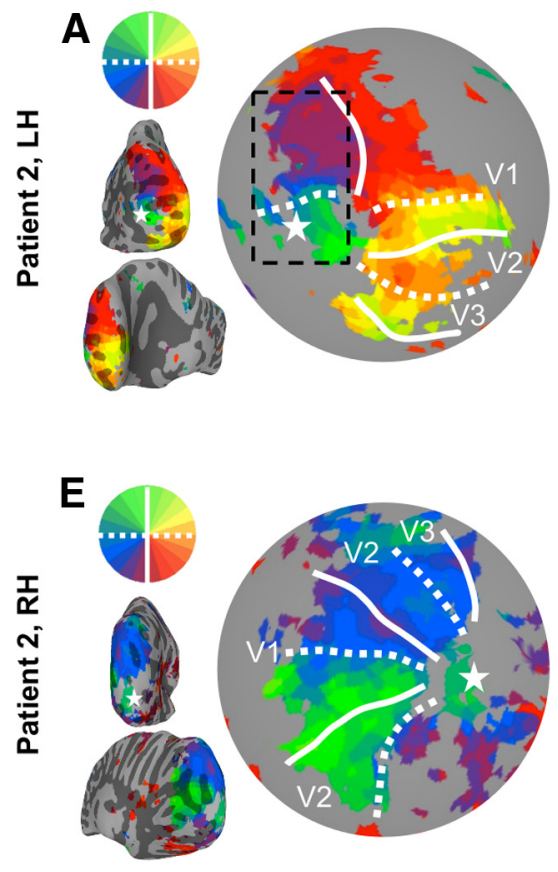

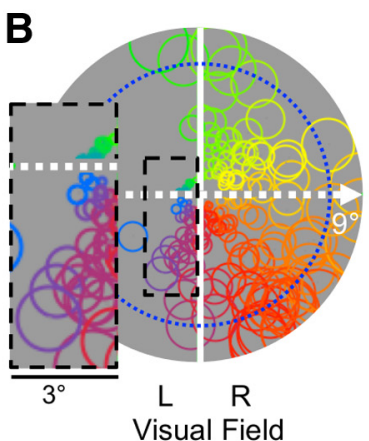

$\mathbf{F}$

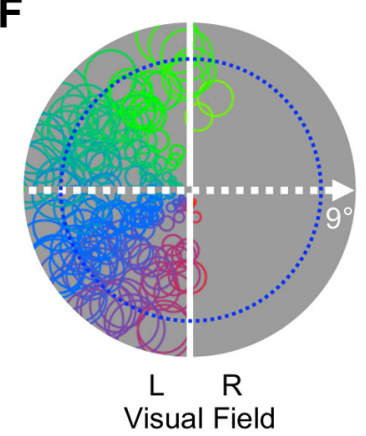

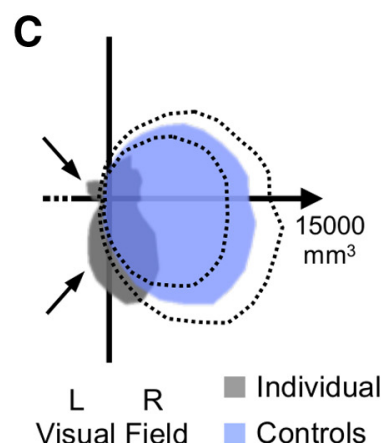

G

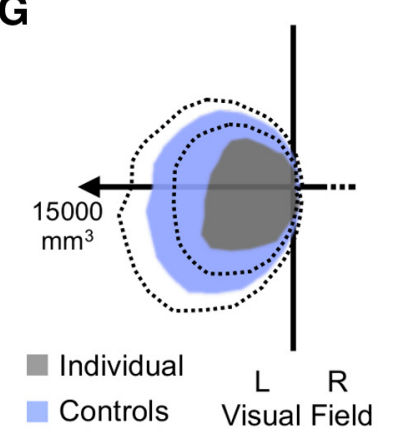

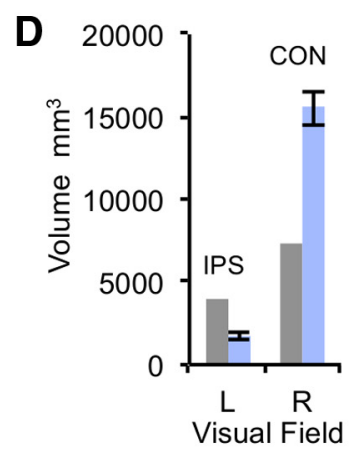

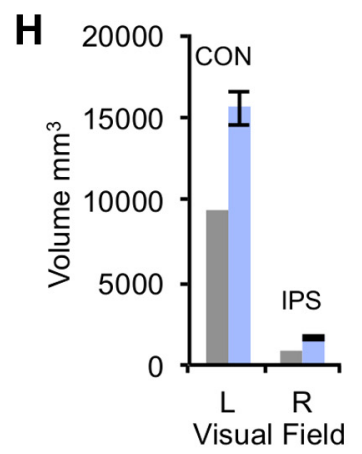

Figure 6. Polar angle retinotopy for patient with congenital cerebral malformation (P2). $\boldsymbol{A}-\boldsymbol{H}$, Figure layout is the same as in Figure 2, with the following exceptions. $\boldsymbol{A}$, Black dashed outlines indicate the approximate location of expanded ipsilateral representation. $\boldsymbol{B}$, Black dashed outlines highlight inset showing expanded ipsilateral representation especially near fovea. $\boldsymbol{B}, \boldsymbol{F}$, Blue dashed outlines encircle the regions corresponding with the visual field perimetry in Figure $7 B$. RH, Right hemisphere; LH, left hemisphere.
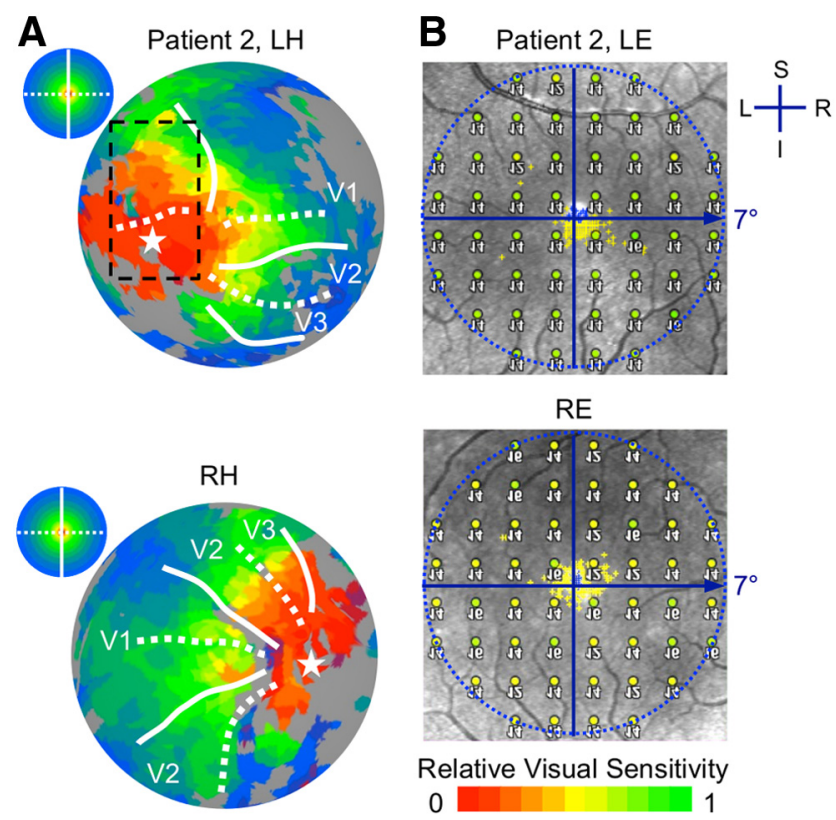

Relative Visual Sensitivity 0

Figure 7. Eccentricity maps and microperimetry for P2. A, Figure panel layout is the same as in Figure 3, except that the black dashed outline and visual area boundaries are as in Figure $6 A, E$. B, Monocular microperimetry plots (LE, left eye; RE, right eye) based on HFA modified 10-2 test presented with an OPKO microperimeter. The color scale for perimetry test points indicates the relative visual sensitivity, from 0 to 1 . Perimetry data points are overlaid on SLO retinal images, which are oriented to correspond to visual field locations. Fixation scatter is indicated by group of yellow and blue + symbols. Blue dashed outlines encircle the regions corresponding with the FFMaps in Figure 6, B and F. L, Left field; R, right field; S, superior field; I, inferior field; $R H$, right hemisphere; LH, left hemisphere. average, the amount of tissue activated by the ipsilateral field in hemispheres with atypical organization was 3.2 times larger than in healthy controls (Fig. 10B, IPS, red vs light blue shading: $4838 \pm 572 \mathrm{vs} 1519 \pm 165 \mathrm{~mm}^{3}$ ). The distributions of the volume of cortex activated by the ipsilateral hemifield were significantly different between groups (two-tailed Wilcoxon rank sums, $n_{\mathrm{A}}=$ $\left.3, n_{\mathrm{C}}=12, W=42, p=0.004\right)$. Moreover, no hemisphere of any individual healthy control had an ipsilateral representation as large as those in the atypical patients (controls, $788-2363 \mathrm{~mm}^{3}$; atypical patients, $3881-5850 \mathrm{~mm}^{3}$ ).

The amount of gray matter in human visual cortex can vary by at least twofold to threefold (Duncan and Boynton, 2003). We reasoned that hemispheres with a greater volume of visually activated cortex would have a generalized expansion of the polar histogram such that both the ipsilateral and contralateral representations would be expanded. Conceivably, our three patients with retinotopic anomalies might have had larger brains. However, it is important to point out that the polar histograms from hemispheres with retinotopic additions (red shading) did not demonstrate a uniform scaling compared with healthy controls (light blue shading), but rather a differential positive scaling of the ipsilateral field and negative scaling of the contralateral representation. On average, the total amount of visually activated cortex (ipsilateral plus contralateral fields) was $16,651 \pm 2837 \mathrm{~mm}^{3}$ in atypical patients and $16,594 \pm 1133 \mathrm{~mm}^{3}$ in healthy controls. The distributions of the total volume of activated cortex were not significantly different between groups (two-tailed Wilcoxon rank sums, $\left.n_{\mathrm{A}}=3, n_{\mathrm{C}}=12, W=24.5, p=0.9626\right)$. Thus, there was no single multiplicative scaling factor that could be applied to the histograms from anomalous hemispheres that would make them comparable to those of the healthy controls. 
A
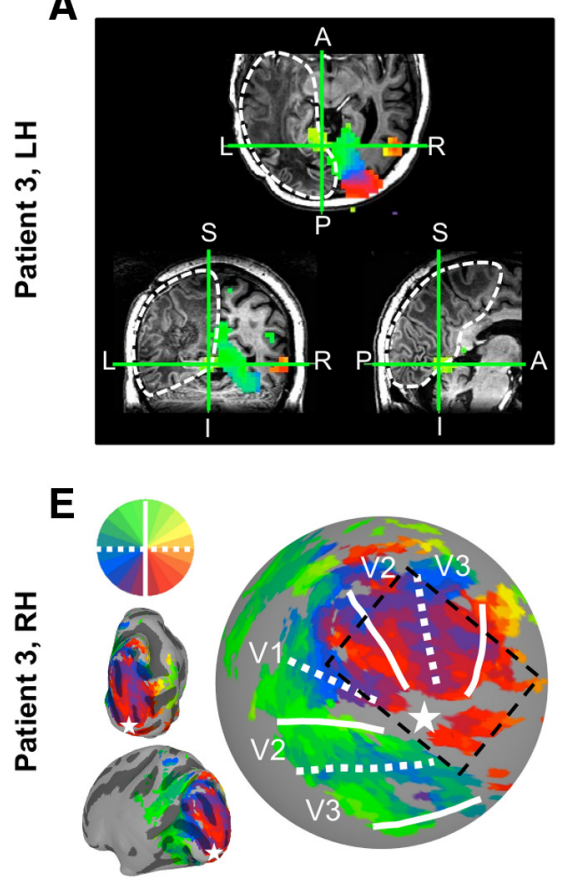

B

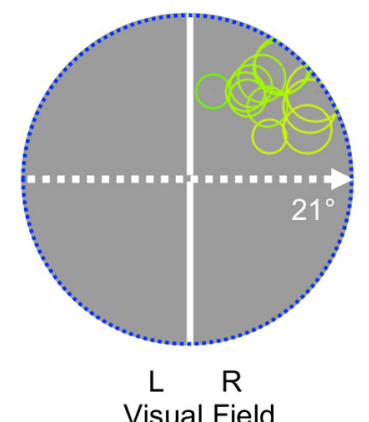

F

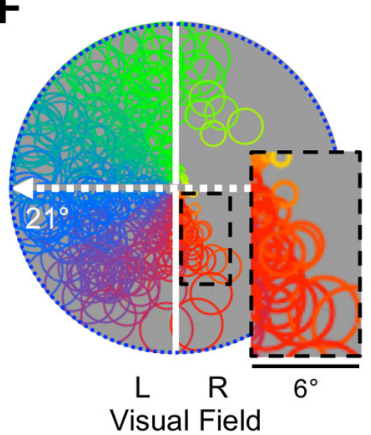

C

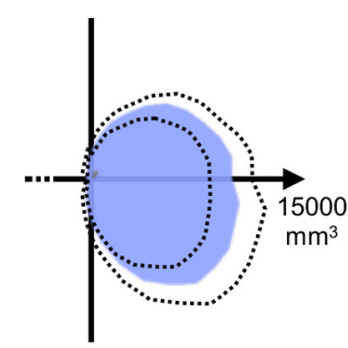

L R Individual Visual Field Controls

G

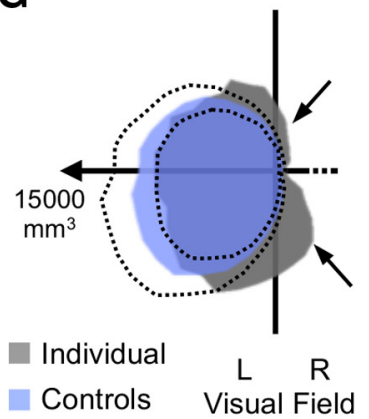

D

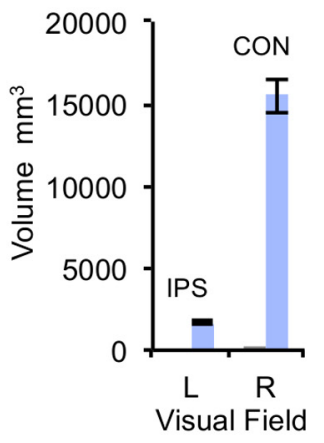

H

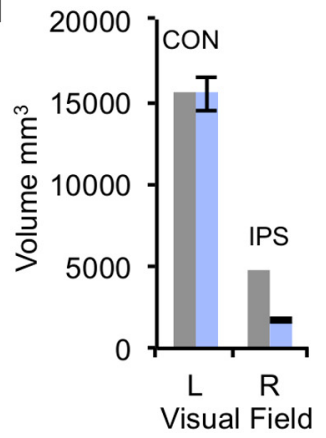

Figure 8. Polar angle retinotopy for patient with a brain tumor in left hemisphere (P3). $\boldsymbol{A}-\boldsymbol{H}$, Figure layout is the same as in Figure 2 , with the following exceptions. $\boldsymbol{A}$, Extensive left hemisphere damage prevented construction of a cortical surface model, so three anatomical views of color-coded polar angle maps are displayed. White dashed outline shows the region of cortical damage. $\mathrm{L}$, Left; R, right; S, superior; I, inferior; A, anterior; P, posterior; RH, right hemisphere; $L H$, left hemisphere. $\boldsymbol{E}$, Black dashed outlines indicate the approximate location of expanded ipsilateral representation. $\boldsymbol{F}$, Black dashed outlines highlight the inset showing expanded ipsilateral representation, especially near the vertical meridian. $\boldsymbol{B}, \boldsymbol{F}$, Blue dashed outlines encircle the regions corresponding with the visual field perimetry in Figure $9 B$.

A
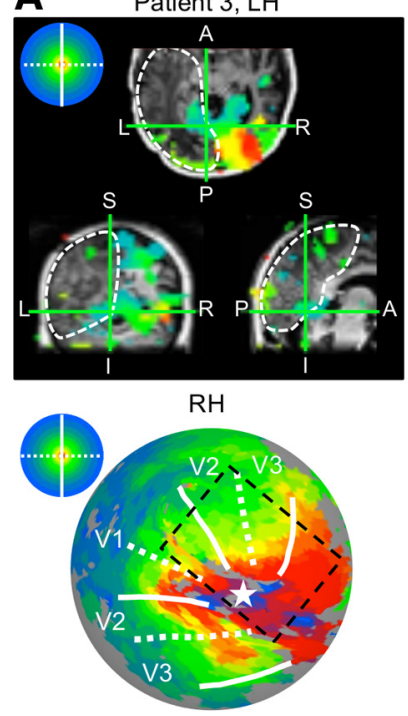

B
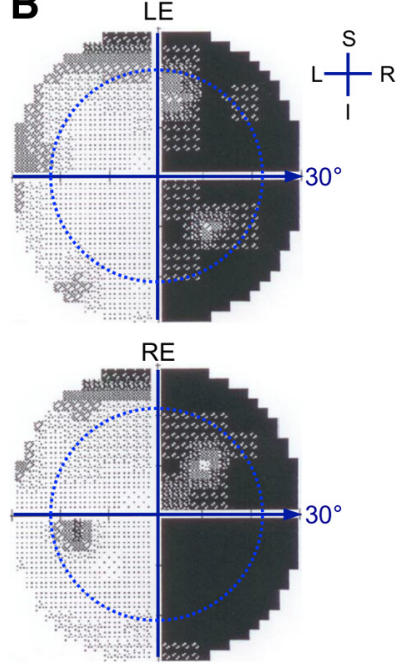

Relative Visual Sensitivity

$0 \square$ Fic 1

Figure 9. Eccentricity maps and perimetry for P3. A, Figure panel layout is the same as in Figure 3, with the following exceptions. A, Top row, Extensive left hemisphere damage prevented construction of cortical surface model, so three views of anatomical colorcoded eccentricity maps are displayed. White dashed outline shows region of cortical damage. L, Left; $R$, right; $S$, superior; I, inferior; $A$, anterior; $P$, posterior. $A$, Bottom row, Black dashed outline and visual area boundaries as in Figure 8E. B, Monocular Humphrey $30-2$ perimetry plots ( $L E$, left eye; $R E$, right eye). Gray scale indicates the relative visual sensitivity, from 0 to 1 . Blue dashed outlines encircle the regions corresponding with the FFMaps in Figure 8, $B$ and F. L, Left field; R, right field; S, superior field; I, inferior field; $R H$, right hemisphere; $L H$, left hemisphere.

Additionally, our results were not dependent upon minor differences that might have occurred in the VOI boundaries between atypical patients and healthy controls. To confirm that the VOIs in healthy controls were not "missing" tissue activated by the ipsilateral field (e.g., in a higher visual area) that might have been included in atypical patients, the same set of analyses described previously were repeated in healthy controls except using expanded VOIs that included all of visual cortex. We observed a scaling of the total amount of visual activation in both the ipsilateral and contralateral visual field, rather than a selective increase of the ipsilateral field. Particularly, the amount of tissue activated by the ipsilateral field in controls with expanded VOIs was $2081 \pm 285 \mathrm{~mm}^{3}$ compared with the $4838 \pm 572 \mathrm{~mm}^{3}$ in atypical patients (Fig. 10A,B, IPS, dark blue vs red). The distributions of the volume of cortex activated by the ipsilateral field remained significantly different between groups (two-tailed Wilcoxon rank sums, $n_{\mathrm{A}}=3, n_{\mathrm{C}}=12, W=41, p=0.009$ ).

\section{Majority of patients with central damage had typical} retinotopic organization

The remaining 22 patients had typical retinotopic organization compared with healthy subjects except for the presence of retinotopic deletions caused by their pathologies. While hemispheres with direct damage did contain "deletions" within their retinotopic maps, the topography for the remainder of the map was comparable to healthy controls. As an alternate control group, an averaged polar histogram was computed from the hemispheres of patients with typical retinotopic organization that did not contain direct pathology (Fig. 10C,D, typical patients shaded light yellow). Compared with healthy controls, patient hemispheres with typical 

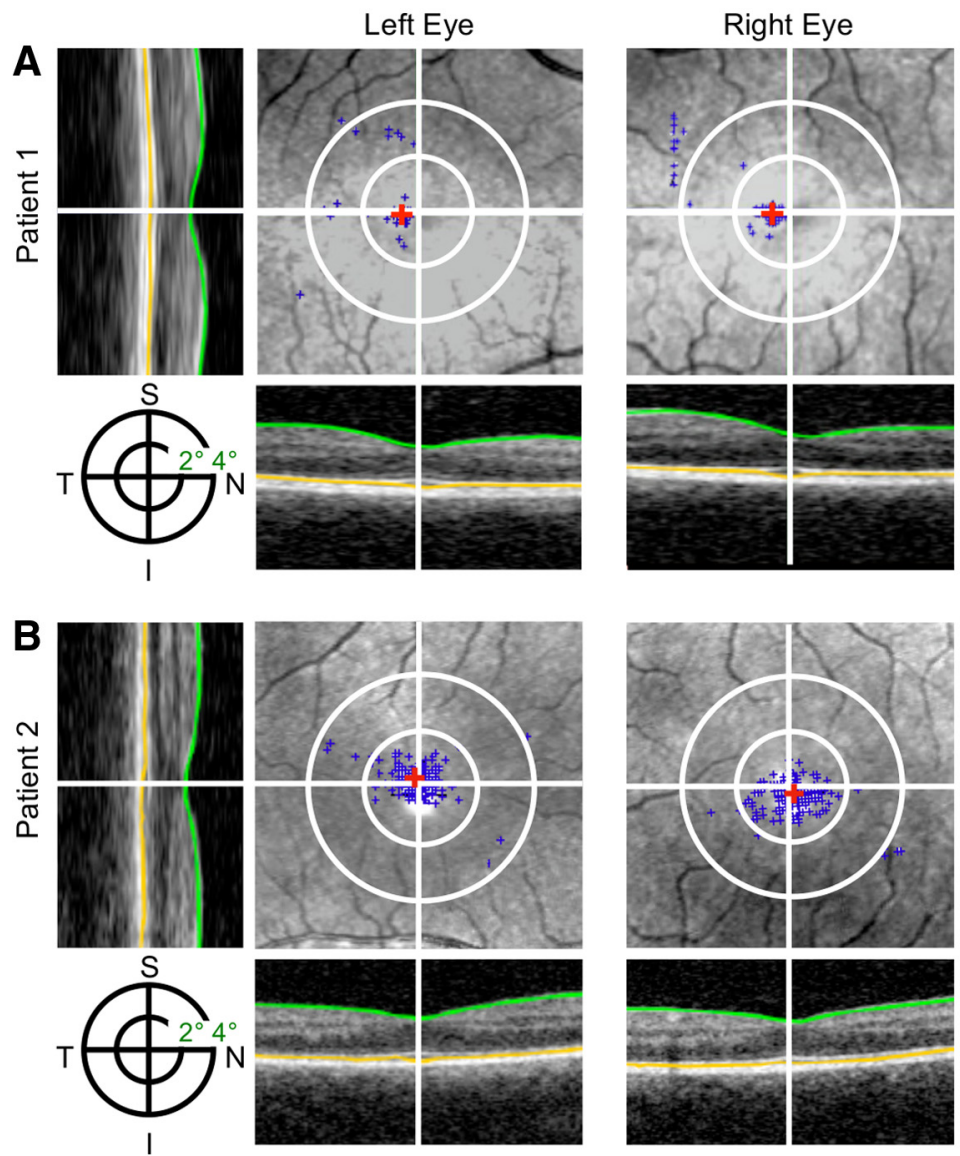

Figure 10. Fixation records for patients $\mathrm{P} 1$ and $\mathrm{P} 2$ with atypical cortical organization. $A, B$, Fixation samples (small blue + symbols) superimposed on $S L 0$ retinal images of $\mathrm{P} 1(\boldsymbol{A})$ and $\mathrm{P} 2(\boldsymbol{B})$. Red + symbol denotes the average fixation location during the 5-7 min sample period. Large white crosshairs denote the center of the foveal pit as determined by OCT images shown below and to the left and right of SLO images. Inner and outer white circles shows the $2^{\circ}$, and $4^{\circ}$ radii from the foveal pit. S, Superior; I, inferior; $\mathrm{T}$, temporal; $\mathrm{N}$, nasal.

organization had a generally smaller amount of tissue activated by both the ipsilateral and contralateral fields (Fig. 10D, light yellow vs blue; IPS: $1242 \pm 173$ vs $1519 \pm 165 \mathrm{~mm}^{3}$; CON: $10,164 \pm 757$ vs $\left.15,075 \pm 1065 \mathrm{~mm}^{3}\right)$. While the distributions of the volume of cortex activated by the ipsilateral field were not significantly different between groups (two-tailed Wilcoxon rank sums, $n_{\mathrm{C}}=12, n_{\mathrm{T}}=22$, $W=247, z=1.318, p=0.187$ ), the distributions of the volume of cortex activated by the contralateral field differed significantly between groups (two-tailed Wilcoxon rank sums, $n_{\mathrm{C}}=12, n_{\mathrm{T}}=22$, $W=303, z=3.334, p=0.001$ ).

We predicted that visual cortex in typical patients may tend to be less responsive during the fMRI task, regardless of visual hemifield. We hypothesized that, if this were the case, the differences between typical patients and healthy controls could be removed by applying a single scaling factor to both the ipsilateral and contralateral field representations of typical patients. To test this hypothesis, we normalized the contralateral field histogram of typical patients to that of healthy controls. This required a scaling factor of $\sim 1.5$, which was then applied to the ipsilateral field histogram of typical patients. After this step, no significant differences remained between the typical patients (Fig. 10C,D, normalized typical patients, dark yellow; IPS: $1842 \pm 257 \mathrm{~mm}^{3}$; CON: 15,075 $1123 \mathrm{~mm}^{3}$ ) and healthy controls in the distributions of the volume of cortex activated by each hemifield (two-tailed Wilcoxon rank sums, $n_{\mathrm{C}}=12, n_{\mathrm{TN}}=22$; IPS: $W=198, z=-0.433, p=0.665$; CON: $W=213, z=-0.090, p=0.928)$. This suggests that most
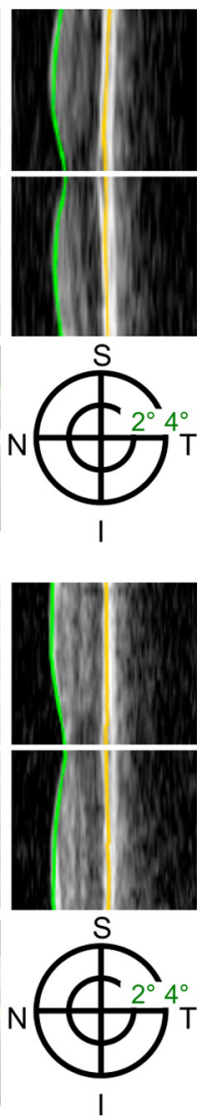

patients with pathology of one hemisphere tended to have topographically normal retinotopic organization in the unaffected hemisphere, though with uniformly less fMRI activation overall.

Last, almost none of the typical patient cases were anatomically and functionally comparable to those of atypical patients. To review, all three atypical patients had evidence for a substantial functional "disconnection" of the vertical meridian representations between hemispheres, due to either (1) a mostly nonfunctional visual cortex (evidenced by the lack of BOLD-fMRI activation and visual field perimetry response) and direct damage within the visual cortex VOI (P1 and P3), or (2) the developmental absence of a corpus callosum (P1). While five patients (P4-P9) with typical retinotopic organization contained a hemisphere that was mostly nonfunctional (Table 1, Func Dis = yes), the pathology in three of the five patients (P6-P9) did not result in direct damage within the visual cortex VOI (Table 1, DD = no). Rather, these patients had damage to the LGN and/or optic radiations that removed the afferent drive to visual cortex. In the other two of five patients (P4 and P5), the pathology resulted in direct damage within the visual cortex VOI (Table $1, \mathrm{DD}=$ yes). Interestingly, though, both of these patients had ipsilateral field representations $\left(\mathrm{P} 4,3263 \mathrm{~mm}^{3}\right.$; $\mathrm{P} 5,3431 \mathrm{~mm}^{3}$ ) that trended toward atypical: they were substantially larger than that of any healthy subject (788-2363 $\mathrm{mm}^{3}$ ), though not as large as that of any patient hemisphere in our atypical group (3881-5850 $\mathrm{mm}^{3}$ ). These findings suggest that simply removing the retino-geniculate input may not be sufficient to acquire an expanded ipsilateral field representation. In such cases, the remaining intrinsic activation within the intact cortex may be sufficient to prevent initial unmasking of the ipsilateral field. Therefore, although two hemispheres can appear to be nonfunctional because they lack fMRI response and the patients have a hemianopia, their potential for expansion of the ipsilateral field representation may be quite different given the underlying pathology/anatomical involvement.

Expanded ipsilateral field representation in atypical patients was not accounted for by eccentric fixation

An important concern is that abnormal fixation in patients with visual pathology could cause artifactual distortions in visual field maps measured with fMRI. Use of a nonfoveal region for fixation, termed an eccentric preferred retinal locus (PRL), is a common adaptive strategy of patients with central visual field deficits. The PRL allows them to place more of the scene of interest within the intact portion of their visual field (for review, see Crossland et al., 2011). While a normal subject will use their central fovea to fixate the center of a visual display, a patient that uses a PRL to the right of their fovea will rotate their eyes to the left to place their PRL at the center of the display. This creates an asymmetrical representation of the visual display on the retina and, consequently, could 
A

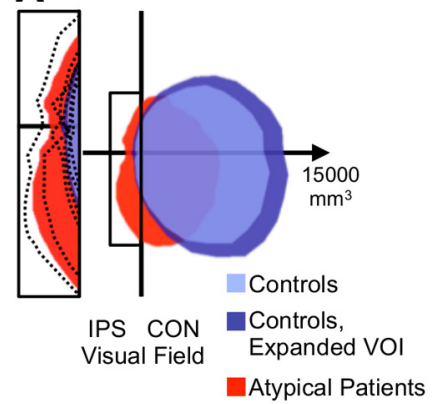

C

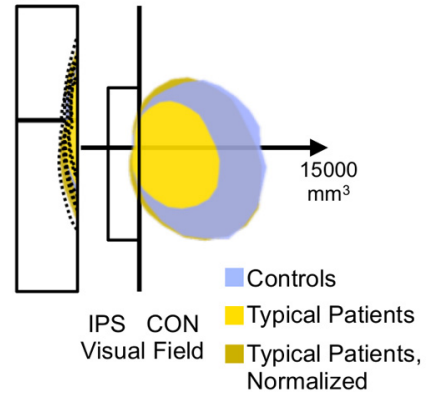

Figure 11. Patients with atypical cortical organization have larger ipsilateral field representations. $\boldsymbol{A}, \boldsymbol{B}$, Group-averaged polar histograms and bar graphs for hemispheres from patients with atypical retinotopic organization (red shading, $n=3$ ), healthy controls (light blue shading, $n=12$ ), and healthy controls with expanded V0ls including all of visual cortex (dark blue shading, $n=12$ ). Black dashed lines in the inset in $\boldsymbol{A}$ and error bars in $\boldsymbol{B}$ show \pm SEM. $\boldsymbol{C}, \boldsymbol{D}$, Group-averaged polar histograms and bar graphs for hemispheres from healthy controls (light blue shading, $n=12$ ), patients with typical retinotopic organization (yellow, $n=22$ ), and patients with typical retinotopic organization that have been normalized to match controls in the total volume of activation (dark yellow, $n=22$ ). Note: different $y$-axis scales in $\boldsymbol{B}$ and $\boldsymbol{D}$ for the ipsilateral versus contralateral visual fields.

create an apparent asymmetry in the measured cortical representation (Baseler et al., 2002).

The use of an eccentric PRL, however, is not consistent with the results of our study. Patients can be classified as having predominately normal central fixation if $>50 \%$ of their preferred fixation points fall within $2^{\circ}$ of the fovea (Fujii et al., 2003). We used an OPKO combined SLO with OCT and microperimetry to track fixation on the retina of two patients with atypical organization (the third patient was no longer available) and found that both had predominately normal central fixation $(70-81 \%$ of fixation points fell within a $2^{\circ}$ diameter of the fovea). More specifically, for both eyes of $\mathrm{P} 1$, the centroid of fixation (Fig. 11A, red + symbol) was $0.64^{\circ}$ to the left of the central foveal pit (white crosshair) identified in OCT. The average distance of fixation points (blue + symbols) from the centroid was $0.38 \pm 0.06^{\circ}$ in the left eye and $0.46 \pm 0.11^{\circ}$ in the right eye. For P2, the centroid of fixation (Fig. $11 B$, red + symbol) was $0.33^{\circ}$ to the left of the central foveal pit (white crosshair) in the left eye and $0.27^{\circ}$ to the right in the right eye. The average distance of fixation points (blue + symbols) from the centroid was $0.66 \pm 0.05^{\circ}$ in the left eye and $0.75 \pm 0.05^{\circ}$ in the right eye. Note that the direction of fixation in the right eye of $\mathrm{P} 2$ is in the opposite direction to that which, if large enough, could theoretically create an artifactual asymmetry involving an expanded representation of the left hemifield in the left hemisphere (as observed in this patient).

In sum, our data suggest that the ipsilateral field expansions were not the result of eccentric PRLs. While we cannot exclude the possibility that P1 and P2 used a fixation locus during the
fMRI experiments different to what was measured here, we have used high-accuracy retinal imaging/tracking to provide the best estimate of their average locus of fixation while fixating a central marker, as they would within the fMRI scanner environment. We found that the center of mass of fixation in both patients was located within the confines of the foveal pit.

\section{Interhemispheric competition: a mechanism for atypical organization?}

As outlined in Figure 12, we can begin to understand our results within the framework of a competitive model that is based on the following four factors. (1) Retino-geniculate afferents to V1 have a region of overlap between hemispheres resulting in a dual representation (one in each hemisphere) of the vertical meridian plus a strip of the ipsilateral field. (2) Normally, interhemispheric connections passing through the corpus callosum simply continue the effects of connectivity that are present throughout the rest of visual cortex. Overall, the net effects of horizontal intracortical connectivity are generally suppressive. (3) Unilateral damage to visual cortex, or the transcallosal connections themselves, relieves the suppression at the "edge" of the visual field representation in the intact hemisphere. Since for V1 this edge represents the vertical meridian and adjacent ipsilateral field, the loss of tonic suppression allows it to expand. In the following section, each of these factors is considered in more detail.

(1) The retino-geniculate afferent pattern (Fig. 12A) provides a small source of ipsilateral visual field representation within V1. This arises from a retinal zone along the vertical meridian (Fig. $12 \mathrm{~A}$, top, red lines) that contains a mixture of ganglion cells projecting either ipsilaterally (more temporally located cells) or contralaterally (more nasally located cells) through the optic chiasm (Stone et al., 1973; Bunt and Minckler, 1977; Bunt et al., 1977; Fukuda et al., 1989). The overlap zone (black dashed outline) spans $\sim 0.5^{\circ}$ in radius near the fovea, extending to $1.5^{\circ}$ more peripherally. Due to the naso-temporal overlap and the topographic nature of the retino-geniculo-striate pathway, the afferent pattern within V1 (Fig. 12A, bottom, red lines) should maintain a bilateral representation of the visual field vertical meridian. Accordingly, single-unit recording in the baboon identified an ipsilateral representation out to $2^{\circ}$ within the first few millimeters of both V1 and V2 along the vertical meridian border (Kennedy et al., 1985). In Figure 12A, we modeled the afferent pattern to $\mathrm{V} 1$ as a smoothly decreasing, spatial gradient representing the contralateral visual field and adjacent ipsilateral field.

(2) Within visual cortex, bilaterally represented regions of the visual field are interconnected through interhemispheric projections (Choudhury et al., 1965; Hubel and Wiesel, 1965; Zeki, 1970; Berlucchi, 1972; Sanides, 1978; Essen and Zeki, 1978; Newsome and Allman, 1980). Functionally, these interhemispheric connections have been hypothesized to reiterate the effects of horizontal connections and/or lateral spread of extrastriate feedback normally present throughout cortex (Van Essen et al., 1982). This characterization reflects the concept that interhemispheric connections are functionally comparable to intrahemispheric connections in that both are cortico-cortico pathways that have similar laminar distributions in primates (largely originating from layer III and terminating in layer IV and above) and a remarkable degree of fine structure in spatial distribution parallel to the cortical surface. Like interhemispheric horizontal connections, feedback projections also spread laterally and can cross via the corpus callosum to terminate in the opposite hemisphere. Therefore, we consider the cortical tissue in each hemisphere as effectively forming a single functional unit that is fully intercon- 
A Retino-Geniculate Afferent Pattern

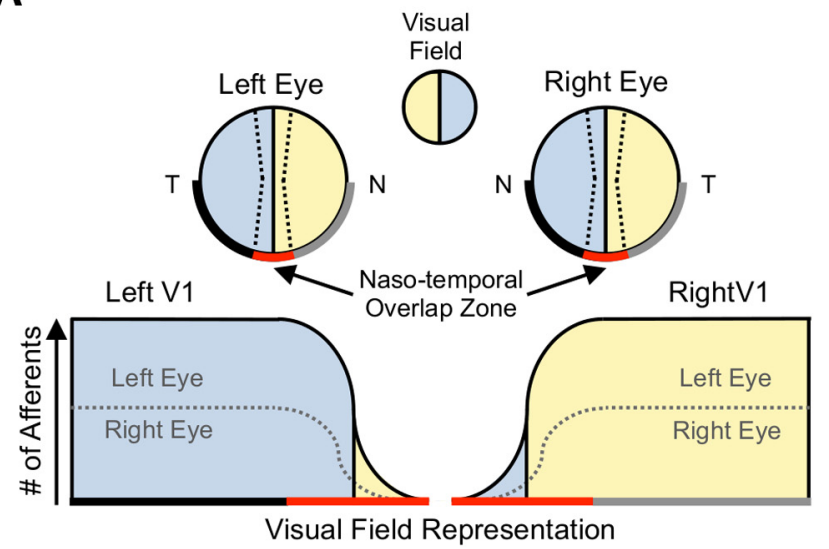

B Effects of Loss of Suppression

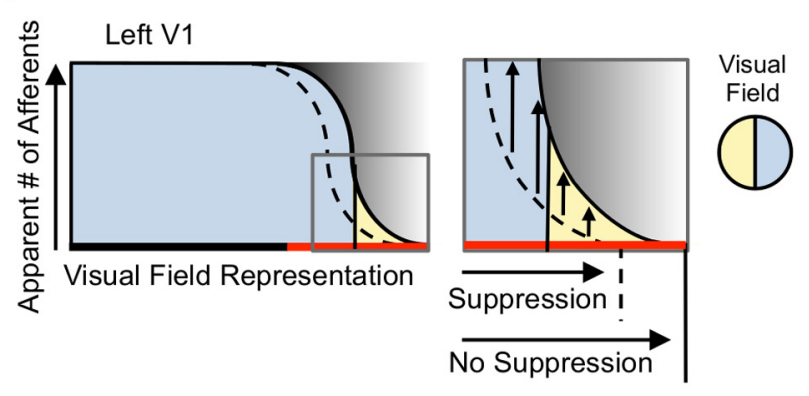

C Retinotopic Expansion of Ipslateral Representation

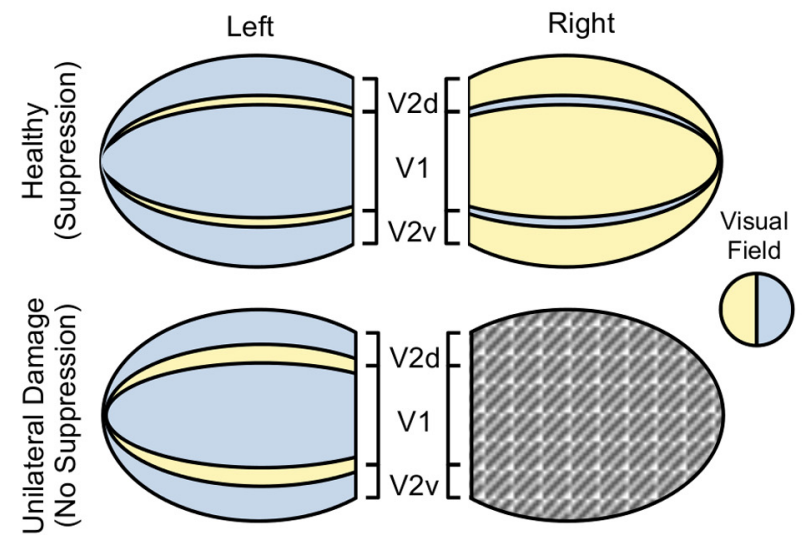

Figure 12. Conceptual model of interhemispheric suppression and effects of unilateral damage on apparent retinotopy. $\boldsymbol{A}$, Schematic of the retino-geniculate afferent pattern into V1, including a naso-temporal overlap zone (highlighted by red lines) providing a source of ipsilateral visual field input to V1 in each hemisphere. $\boldsymbol{B}$, Tonic suppression along the edge of each hemisphere (left V1 only shown for clarity) reduces the apparent number of retino-geniculate afferents (black dashed curve) along the naso-temporal overlap zone. Inset: the effect of a loss of suppression is an increase in the apparent number of afferents. C, Schematic model of flattened visual cortex highlighting the V1/V2 border at the representation of the ipsilateral field (thin contrasting colored strip). Compared with healthy visual cortex (top), unilateral damage (bottom) to the right hemisphere causes expansion of the visual field representation near the vertical meridian, including the ipsilateral field.

nected by a uniform network involving intrahemispheric and interhemispheric connections in a similar fashion.

Overall, the net effects of intrahemispheric connections are generally suppressive. It is typically thought that receptive fields of visual cortex neurons are organized into two or more spatially concentric zones (not necessarily circular) often referred to as the center, "near" surround, and "far" (or nonclassical) surround
(Allman et al., 1985; Angelucci and Bressloff, 2006). Though interactions among these regions can be complex, it is common for the surrounds to exert an antagonistic (e.g., suppressive) effect on the center response, especially for stimulus patterns that extend uniformly over both center and surround regions. Indeed, recent recordings of synaptic conductances in awake (but not anesthetized) animals suggest that cortical responses to visual stimulation are typically dominated by synaptic inhibition that has "extremely broad spatial selectivity" (Haider et al., 2013). Such "suppressive" interactions can be mediated by a variety of quite general neurophysiological mechanisms, including lateral and feedback inhibition (Hartline, 1949; Kuffler, 1953; Angelucci and Bressloff, 2006), divisive normalization (Carandini and Heeger, 1994, 2012), or other nonlinear processes (Priebe and Ferster, 2012). A key feature of these mechanisms is often that the suppressive effects appear to be driven from surround distances that extend at least as far (Stettler et al., 2002) or farther than the distances covered by the center excitatory interactions. For instance, divisive normalization is based on the notion that each neuron's center response is "divided" by the activity of neighboring neurons pooled over an extended "surround." Similarly, "biased competition" models of attention posit ubiquitous tonic suppression among arrays of multiple stimuli that is relieved only when one stimulus gains a competitive edge through attention (Desimone and Duncan, 1995; Luck et al., 1997). To the extent that such spatial interactions must be mediated in some fashion by laterally spreading connections either within or between cortical visual areas, it follows from above that these interactions also generally spread between the hemispheres.

Of particular interest here is the zone of interhemispheric suppression along the edge of the visual field representation in each hemisphere (the bilaterally represented regions). In a healthy intact brain, the resulting effects of a tonic suppression along the edge of each hemisphere would be to decrease the apparent number of retino-geniculate afferents along the vertical meridian (Fig. 12B, black dashed curve) compared with that of the retino-geniculate afferents alone (Fig. 12B, solid black curve).

(3) Based on this mechanism, the third and final factor posits that unilateral damage to visual cortex, or pathology of the corpus callosum, would disrupt the tonic suppression and cause retinotopic unmasking (increases in activation) along the vertical meridian representation (Fig. 12B, inset). Topographically, this would appear as an expansion of the ipsilateral visual field representation (yellow) plus an expansion of an adjacent zone of the contralateral field (blue). Figure $12 \mathrm{C}$ shows this effect in a schematic model of flattened visual cortex (Polimeni et al., 2006; Schira et al., 2007) that highlights the V1/V2 border at the representation of the vertical meridian. This competitive model is consistent with the retinotopic expansion of the existing vertical meridian representations observed in V1/V2 of $\mathrm{P} 1-\mathrm{P} 3$ as well as V3/V3A of P1 and P2. Additionally, patients P1 and P2 had an apparently ectopic (topographically displaced) representation of the ipsilateral visual field within lateral occipital cortex that is normally associated with visual areas V3/V3A (and possibly other areas). Interhemispheric competition within extrastriate cortical areas including crossed feedback projections from hierarchically higher to lower cortical levels may provide a functionally similar mechanism, but such speculations are reserved for the Discussion.

While the elimination of interhemispheric competition might constitute one plausible mechanism for the ipsilateral expansion observed here, other mechanisms might also contribute. Ample evidence suggests that the receptive fields of cells within a zone of 
deafferented visual cortex can undergo activity-dependent plastic reorganization (axonal sprouting and synaptogenesis), resulting in atypical cortical retinotopic patterns in which the receptive fields of initially deafferented neurons become responsive to stimuli presented near the margins of the scotoma. Such reorganization can be associated with the strengthening of long-range excitatory connections that normally support perceptual effects such as contour integration but after reorganization may support perceptual "filling-in" of contours crossing a scotoma (Gilbert and $\mathrm{Li}, 2012$ ). In the present context, though, neurons representing the midline in the intact hemisphere are not deprived of their afferent input; they have lost only their "lateral" and feedback connections from the opposite hemisphere. It is not clear whether this would be sufficient to trigger strengthening of the remaining horizontal excitatory connections within the intact hemisphere. If it did, the anticipated effect would be to "pull" the receptive fields toward the intact contralateral hemifield, not the disconnected/lesioned ipsilateral field.

\section{Discussion}

We used a unique database of fMRI vision maps in patients with central brain pathology to identify anomalies in visual cortex organization elicited by adult $(n=27)$ as well as congenital pathology $(n=2)$. Of these patients, we identified three with atypical retinotopic organization consisting of an expanded ipsilateral visual field representation when compared with healthy controls. This pattern was observed in patients with adult-onset damage $(n=2)$ as well as congenital cerebral malformation $(n=1)$. In two of these cases (one adult-onset, one congenital), an ectopic or topographically displaced representation of the ipsilateral field was apparent. Our results suggest that visual cortex can undergo large-scale retinotopic changes elicited by adult and congenital pathologies. Our large sample of patients having a variety of different pathologies allows us to estimate the rate of incidence for this phenomenon and suggests that it is relatively rare $(\sim 10 \%)$ among patients with central visual pathology in general.

To our knowledge, this is the largest investigation to date of fMRI-based retinotopic mapping in human patients with central damage to the visual cortex. Our results add to previous claims of retinotopic reorganization within a local zone of deafferented cortex, as can occur within primary visual cortex after peripheral binocular retinal pathologies (Baseler et al., 2002; Baker et al., 2005, 2008) or damage to the optic radiations (Dilks et al., 2007), and within extrastriate cortex after selective damage to primary visual cortex (Baseler et al., 1999). In such cases, the deafferented region of cortex [termed the lesion projection zone (LPZ)] becomes responsive to visual input from surrounding portions of the visual field. This form of reorganization is associated with axonal sprouting and synaptogenesis of long-range horizontal connections within cortex adjacent to the LPZ (Darian-Smith and Gilbert, 1994; Yamahachi et al., 2009). However, patients in the present study differ from such patients with peripheral pathologies in three ways. (1) Many patients in our study have direct damage to visual cortex. In contrast, patients with peripheral pathologies have an intact visual cortex that has been partially deafferented. (2) Our patients with atypical organization have responses to the ipsilateral visual field within cortex that would normally represent the contralateral visual field. (3) We observed local expansions of the visual field that were consistent with normal retinotopy and, in two patients, additional ipsilateral field representations that appeared to be ectopic. Patients with peripheral pathologies typically gain responses within the LPZ to retinotopic locations that are normally represented in cortex surrounding the LPZ. In other words, the expansion is topographically consistent with the normal pattern.

Ectopic representation of the ipsilateral visual field has been previously observed in cases of developmental misrouting of the optic nerve/tract in patients that were albinotic (Morland et al., 2001; Hoffmann et al., 2003; Klemen et al., 2012), ahemispheric (Muckli et al., 2009), and achiasmic (Hoffmann et al., 2012). In contrast to patients in our study, patients with peripheral misrouting have an ipsilateral field representation that is coextensive with the normal contralateral field representation within a hemisphere. Thus, voxel (population) receptive fields have bilateral responses, perhaps from two different populations of neurons- one responding to the normal contralateral input and the other responding to the atypical ipsilateral input. There have also been reports of activation in the ipsilateral extrastriate cortex in patients with hemispherectomy (Bittar et al., 1999) and stroke (Nelles et al., 2007) as well as along the V1/V2 border in a patient who underwent visual restoration training (Henriksson et al., 2007). However, these studies did not map the topographic organization, if any, of the ipsilateral representation or, in the latter case, was a control group included to assist in the interpretation of the findings.

As detailed above, our results can be understood within the framework of a competitive model in which unilateral damage (or pathology of the corpus callosum) acts to remove interhemispheric suppression from the intact visual cortex and thereby unmask retino-geniculate afferents representing the vertical meridian and ipsilateral visual field (Fig. 12). Similar types of interactions may account for the displaced ipsilateral field representations that we observed in lateral occipital cortex normally associated with visual areas V3/V3A (and possibly other areas). In healthy individuals, it has been shown that under appropriate conditions these regions respond to isolated stimulation of the ipsilateral field even though conventional visual field mapping shows a dominant contralateral field representation (Tootell et al., 1998). Though such ipsilateral influences might be conveyed by callosal input, extrastriate visual areas (particularly dorsal stream) in primates, and probably in humans, also receive retinal input via a colliculo-pulvinar route that may be either modulatory or driving (for review, see Kaas and Lyon, 2007). For instance, evidence exists for activation in V2 and V3A that does not depend on V1 (Girard and Bullier, 1989; Girard et al., 1991). While little is known about the degree of midline overlap within the pulvinar, receptive fields within a region of lateral pulvinar were found to frequently overlap the ipsilateral hemifield by up to $4.8^{\circ}$ among receptive fields centered within the central $7^{\circ}$ of the fovea (Bender, 1981; Abbott, 2009). It is conceivable that the degree of midline overlap within the pulvinar is larger than for the geniculostriate input but is normally suppressed in the cortex by the more extensive and dominant contralateral representation. Moreover, there are multiple intrahemispheric pathways that could distribute such alternative sources of ipsilateral input including feedback circuits at each cortical stage, which, if "unmasked," might appear as an apparently ectopic ipsilateral field representation.

Finally, we cannot rule out the possibility that unique patterns of cortical damage might enable experience-dependent reorganization in ways that differ from those associated with peripheral damage. For instance, perceptual learning is associated with changes in receptive field properties within early visual cortex (e.g., orientation tuning: Leidig et al., 1992; Darian-Smith and Gilbert, 1994; Schoups et al., 2001) and increases in activation (e.g., contrast discrimination: Girard and Bullier, 1989; texture 
discrimination: Galea and Darian-Smith, 1994). Similar processes may occur in patients with cortical damage that engage in visual rehabilitative therapies, which attempt to expand the size of the residual visual field. Claims have been made for success in some, but not all, patients (for review, see Pouget et al., 2012). Definitive cortical mapping studies with such patients have been lacking, so it is unclear whether there are distinctive patterns of cortical damage that differentiate cases of successful versus unsuccessful therapy. It is possible that the success or failure of rehabilitation for each particular patient may depend on the specific pattern of cortical damage and its interaction with mechanisms such as interhemispheric competition that, when disrupted, may mediate visual field expansions. Though the expanded size of the ipsilateral field measured in this study may seem relatively small, an increase of only a few degrees near the fovea could make a major difference in critical visual functions that are predominately foveal, such as reading. Understanding the conditions under which visual field expansions can occur, and careful consideration of the neural mechanisms that might be involved, could lead to greater insight into the potential for effective visual rehabilitation.

\section{References}

Abbott A (2009) Opening up brain surgery. Nature 461:866-868. CrossRef Medline

Allman J, Miezin F, McGuinness E (1985) Stimulus specific responses from beyond the classical receptive field: neurophysiological mechanisms for local-global comparisons in visual neurons. Annu Rev Neurosci 8:407430. CrossRef Medline

Angelucci A, Bressloff PC (2006) Contribution of feedforward, lateral and feedback connections to the classical receptive field center and extraclassical receptive field surround of primate V1 neurons. Prog Brain Res 154:93-120. CrossRef Medline

Baker CI, Peli E, Knouf N, Kanwisher NG (2005) Reorganization of visual processing in macular degeneration. J Neurosci 25:614-618. CrossRef Medline

Baker CI, Dilks DD, Peli E, Kanwisher N (2008) Reorganization of visual processing in macular degeneration: replication and clues about the role of foveal loss. Vision Res 48:1910-1919. CrossRef Medline

Bandettini PA, Jesmanowicz A, Wong EC, Hyde JS (1993) Processing strategies for time-course data sets in functional MRI of the human brain. Magn Reson Med 30:161-173. CrossRef Medline

Baseler HA, Morland AB, Wandell BA (1999) Topographic organization of human visual areas in the absence of input from primary cortex. J Neurosci 19:2619-2627. Medline

Baseler HA, Brewer AA, Sharpe LT, Morland AB, Jägle H, Wandell BA (2002) Reorganization of human cortical maps caused by inherited photoreceptor abnormalities. Nat Neurosci 5:364-370. CrossRef Medline

Bender DB (1981) Retinotopic organization of macaque pulvinar. J Neurophysiol 46:672-693. Medline

Berlucchi G (1972) Anatomical and physiological aspects of visual functions of corpus callosum. Brain Res 37:371-392. CrossRef Medline

Bittar RG, Ptito M, Faubert J, Dumoulin SO, Ptito A (1999) Activation of the remaining hemisphere following stimulation of the blind hemifield in hemispherectomized subjects. Neuroimage 10:339-346. CrossRef Medline

Bunt AH, Minckler DS (1977) Foveal sparing. New anatomical evidence for bilateral representation of the central retina. Arch Ophthalmol 95:1445-1447. CrossRef Medline

Bunt AH, Minckler DS, Johanson GW (1977) Demonstration of bilateral projection of the central retina of the monkey with horseradish peroxidase neuronography. J Comp Neurol 171:619-630. CrossRef Medline

Carandini M, Heeger DJ (1994) Summation and division by neurons in primate visual cortex. Science 264:1333-1336. CrossRef Medline

Carandini M, Heeger DJ (2012) Normalization as a canonical neural computation. Nat Rev Neurosci 13:51-62. CrossRef Medline

Chen FK, Patel PJ, Xing W, Crossland MD, Bunce C, Rubin GS, Da Cruz L (2011) Intrasession repeatability of fixation stability assessment with the Nidek MP-1. Optom Vis Sci 88:742-750. CrossRef Medline
Choudhury BP, Whitteridge D, Wilson ME (1965) The function of the callosal connections of the visual cortex. Q J Exp Physiol Cogn Med Sci 50:214-219. Medline

Cox RW (1996) AFNI: software for analysis and visualization of functional magnetic resonance neuroimages. Comput Biomed Res 29:162-173. CrossRef Medline

Crossland MD, Engel SA, Legge GE (2011) The preferred retinal locus in macular disease: toward a consensus definition. Retina 31:2109-2114. CrossRef Medline

Darian-Smith C, Gilbert CD (1994) Axonal sprouting accompanies functional reorganization in adult cat striate cortex. Nature 368:737-740. CrossRef Medline

Desimone R, Duncan J (1995) Neural mechanisms of selective visual attention. Annu Rev Neurosci 18:193-222. CrossRef Medline

DeYoe EA, Carman GJ, Bandettini P, Glickman S, Wieser J, Cox R, Miller D, Neitz J (1996) Mapping striate and extrastriate visual areas in human cerebral cortex. Proc Natl Acad Sci U S A 93:2382-2386. CrossRef Medline

DeYoe EA, Ulmer J, Mueller WM, Hacein-Bey L, Szeder V, Maciejewski MJ, Medler K, Reitsma D, Mathis J (2011) FMRI of human visual pathways. In: Functional neuroradiology: principles and clinical applications (Faro S, Mohamed FB, eds), pp 485-511. New York: Springer.

Dilks DD, Serences JT, Rosenau BJ, Yantis S, McCloskey M (2007) Human adult cortical reorganization and consequent visual distortion. J Neurosci 27:9585-9594. CrossRef Medline

Duncan RO, Boynton GM (2003) Cortical magnification within human primary visual cortex correlates with acuity thresholds. Neuron 38:659671. CrossRef Medline

Engel SA, Rumelhart DE, Wandell BA, Lee AT, Glover GH, Chichilnisky EJ, Shadlen MN (1994) fMRI of human visual cortex. Nature 369:525. CrossRef Medline

Engel SA, Glover GH, Wandell BA (1997) Retinotopic organization in human visual cortex and the spatial precision of functional MRI. Cereb Cortex 7:181-192. CrossRef Medline

Fujii GY, De Juan E Jr, Humayun MS, Sunness JS, Chang TS, Rossi JV (2003) Characteristics of visual loss by scanning laser ophthalmoscope microperimetry in eyes with subfoveal choroidal neovascularization secondary to age-related macular degeneration. Am J Ophthalmol 136:1067-1078. CrossRef Medline

Fukuda Y, Sawai H, Watanabe M, Wakakuwa K, Morigiwa K (1989) Nasotemporal overlap of crossed and uncrossed retinal ganglion cell projections in the Japanese monkey (Macaca fuscata). J Neurosci 9:2353-2373. Medline

Galea MP, Darian-Smith I (1994) Multiple corticospinal neuron populations in the macaque monkey are specified by their unique cortical origins, spinal terminations, and connections. Cereb Cortex 4:166-194. CrossRef Medline

Gilbert CD, Li W (2012) Adult visual cortical plasticity. Neuron 75:250 264. CrossRef Medline

Girard P, Bullier J (1989) Visual activity in area V2 during reversible inactivation of area 17 in the macaque monkey. J Neurophysiol 62:1287-1302. Medline

Girard P, Salin PA, Bullier J (1991) Visual activity in areas V3a and V3 during reversible inactivation of area V1 in the macaque monkey. J Neurophysiol 66:1493-1503. Medline

Haider B, Häusser M, Carandini M (2013) Inhibition dominates sensory responses in the awake cortex. Nature 493:97-100. CrossRef Medline

Hartline HK (1949) Inhibition of activity of visual receptors by illuminating nearby retinal areas in the Limulus eye. Fed Proc 8:69.

Henriksson L, Raninen A, Näsänen R, Hyvärinen L, Vanni S (2007) Training-induced cortical representation of a hemianopic hemifield. J Neurol Neurosurg Psychiatry 78:74-81. CrossRef Medline

Hoffmann MB, Tolhurst DJ, Moore AT, Morland AB (2003) Organization of the visual cortex in human albinism. J Neurosci 23:8921-8930. Medline

Hoffmann MB, Kaule FR, Levin N, Masuda Y, Kumar A, Gottlob I, Horiguchi H, Dougherty RF, Stadler J, Wolynski B, Speck O, Kanowski M, Liao YJ, Wandell BA, Dumoulin SO (2012) Plasticity and stability of the visual system in human achiasma. Neuron 75:393-401. CrossRef Medline

Holmes G, Lister WT (1916) Disturbances of vision from cerebral lesions, with special refernce to the cortical representation of the macula. Brain 39:34-73. CrossRef 
Horton JC, Hoyt WF (1991) The representation of the visual field in human striate cortex. A revision of the classic holmes map. Arch Ophthalmol 109:816-824. CrossRef Medline

Hubel DH, Wiesel TN (1965) Receptive fields and functional architecture in two nonstriate areas (18 and 19) of the cat. J Neurophysiol 28:229-289. Medline

Hubel DH, Wiesel TN (1970) The period of susceptibility to the physiological effects of unilateral eye closure in kittens. J Physiol 206:419-436. Medline

Hubel DH, Wiesel TN (1977) Ferrier lecture. Functional architecture of macaque monkey visual cortex. Proc R Soc Lond B Biol Sci 198:1-59. CrossRef Medline

Inouye T (1909) Die Sehstorungen bei Schussverletzungen der kortikalen Sehsphare. Leipzig, Germany:W Engelmann.

Jesmanowicz A, Bandettini PA, Hyde JS (1998) Single-shot half k-space high-resolution gradient-recalled EPI for fMRI at 3 Tesla. Magn Reson Med 40:754-762. CrossRef Medline

Kaas JH, Lyon DC (2007) Pulvinar contributions to the dorsal and ventral streams of visual processing in primates. Brain Res Rev 55:285-296. CrossRef Medline

Kennedy H, Bullier J (1985) A double-labeling investigation of the afferent connectivity to cortical areas V1 and V2 of the macaque monkey. J Neurosci 5:2815-2830.

Klemen J, Hoffmann MB, Chambers CD (2012) Cortical plasticity in the face of congenitally altered input into V1. Cortex 48:1362-1365. CrossRef Medline

Kuffler SW (1953) Discharge patterns and functional organization of mammalian retina. J Neurophysiol 16:37-68. Medline

Leidig M, Schmiedecke T, John S, Mann J, Weber M (1992) Spontaneous kidney rupture as an early complication of Wegener's granulomatosis. Dtsch Med Wochenschr 117:455-459. CrossRef Medline

Luck SJ, Chelazzi L, Hillyard SA, Desimone R (1997) Neural mechanisms of spatial selective attention in areas V1, V2, and V4 of macaque visual cortex. J Neurophysiol 77:24-42. Medline

Morland AB, Baseler HA, Hoffmann MB, Sharpe LT, Wandell BA (2001) Abnormal retinotopic representations in human visual cortex revealed by fMRI. Acta Psychol (Amst) 107:229-247. CrossRef Medline

Muckli L, Naumer MJ, Singer W (2009) Bilateral visual field maps in a patient with only one hemisphere. Proc Natl Acad Sci U S A 106: 13034-13039. CrossRef Medline

Nelles G, de Greiff A, Pscherer A, Forsting M, Gerhard H, Esser J, Diener HC (2007) Cortical activation in hemianopia after stroke. Neurosci Lett 426: 34-38. CrossRef Medline

Newsome WT, Allman JM (1980) Interhemispheric connections of visual cortex in the owl monkey, Aotus trivirgatus, and the bushbaby, Galago senegalensis. J Comp Neurol 194:209-233. CrossRef Medline

Polimeni JR, Balasubramanian M, Schwartz EL (2006) Multi-area visuotopic map complexes in macaque striate and extra-striate cortex. Vision Res 46:3336-3359. CrossRef Medline

Pouget MC, Lévy-Bencheton D, Prost M, Tilikete C, Husain M, JacquinCourtois S (2012) Acquired visual field defects rehabilitation: critical review and perspectives. Ann Phys Rehabil Med 55:53-74. CrossRef Medline
Priebe NJ, Ferster D (2012) Mechanisms of neuronal computation in mammalian visual cortex. Neuron 75:194-208. CrossRef Medline

Saad ZS, Ropella KM, Cox RW, DeYoe EA (2001) Analysis and use of FMRI response delays. Hum Brain Mapp 13:74-93. CrossRef Medline

Saad ZS, DeYoe EA, Ropella KM (2003) Estimation of FMRI response delays. Neuroimage 18:494-504. CrossRef Medline

Sabates FN, Vincent RD, Koulen P, Sabates NR, Gallimore G (2011) Normative data set identifying properties of the macula across age groups: integration of visual function and retinal structure with microperimetry and spectraldomain optical coherence tomography. Retina 31:1294-1302. CrossRef Medline

Sanides D (1978) The retinotopic distribution of visual callosal projections in the suprasylvian visual areas compared to the classical visual areas (17, $18,19)$ in the cat. Exp Brain Res 33:435-443. Medline

Schira MM, Wade AR, Tyler CW (2007) Two-dimensional mapping of the central and parafoveal visual field to human visual cortex. J Neurophysiol 97:4284-4295. CrossRef Medline

Schoups A, Vogels R, Qian N, Orban G (2001) Practising orientation identification improves orientation coding in V1 neurons. Nature 412: 549-553. CrossRef Medline

Sereno MI, Dale AM, Reppas JB, Kwong KK, Belliveau JW, Brady TJ, Rosen BR, Tootell RB (1995) Borders of multiple visual areas in humans revealed by functional MRI. Science 268:889-893. CrossRef Medline

Spalding JM (1952) Wounds of the visual pathway. J Neurol Neurosurg Psychiatry 15:169-183. CrossRef Medline

Stettler DD, Das A, Bennett J, Gilbert CD (2002) Lateral connectivity and contextual interactions in macaque primary visual cortex. Neuron 36: 739-750. CrossRef Medline

Stone J, Leicester J, Sherman SM (1973) The naso-temproal division of the monkey's retina. J Comp Neurol 150:333-348. CrossRef Medline

Tootell RB, Mendola JD, Hadjikhani NK, Liu AK, Dale AM (1998) The representation of the ipsilateral visual field in human cerebral cortex. Proc Natl Acad Sci U S A 95:818-824. CrossRef Medline

Van Essen DC, Zeki SM (1978) The topographic organization of rhesus monkey prestriate cortex. J Physiol 277:193-226.

Van Essen DC, Newsome WT, Bixby JL (1982) The pattern of interhemispheric connections and its relationship to extrastriate visual areas in the macaque monkey. J Neurosci 2:265-283. Medline

Van Essen DC, Drury HA, Dickson J, Harwell J, Hanlon D, Anderson CH (2001) An integrated software suite for surface-based analyses of cerebral cortex. J Am Med Inform Assoc 8:443-459. CrossRef Medline

Wandell BA, Smirnakis SM (2009) Plasticity and stability of visual field maps in adult primary visual cortex. Nat Rev Neurosci 10:873-884. CrossRef Medline

Wiesel TN, Hubel DH (1963) Single-cell responses in striate cortex of kittens deprived of vision in one eye. J Neurophysiol 26:1003-1017. Medline

Yamahachi H, Marik SA, McManus JN, Denk W, Gilbert CD (2009) Rapid axonal sprouting and pruning accompany functional reorganization in primary visual cortex. Neuron 64:719-729. CrossRef Medline

Zeki SW (1970) Interhemispheric connections of prestriate cortex in monkey. Brain Res 9:63-75. Medline 